\title{
INTRA- AND INTER-INDUSTRY PRODUCTIVITY SPILLOVERS IN OECD MANUFACTURING: A SPATIAL ECONOMETRIC PERSPECTIVE
}

\author{
HARALD BADINGER \\ PETER EGGER
}

CESIFO WORKING PAPER NO. 2181

CATEGORY 9: INDUSTRIAL ORGANISATION

JANUARY 2008
An electronic version of the paper may be downloaded
- from the SSRN website:
- from the RePEc website:
- from the CESifo website:
www.SSRN.com
www.RePEc.org
www.CESifo-group.org/wp




\title{
INTRA- AND INTER-INDUSTRY PRODUCTIVITY SPILLOVERS IN OECD MANUFACTURING: A SPATIAL ECONOMETRIC PERSPECTIVE
}

\begin{abstract}
We adopt a spatial econometric approach to estimate intra- and inter-industry productivity spillovers in total factor productivity transmitted through input-output relations in a sample of 13 OECD countries and 15 manufacturing industries. Both R\&D spillovers as well as remainder, input-output-related linkage effects are accounted for, the latter of which we model by a spatial regressive error process. We find that knowledge spillovers occur both horizontally and vertically, whereas remainder spillovers are primarily of intra-industry type. Notably, these intra-industry remainder spillovers turn out economically more significant than R\&D spillovers.
\end{abstract}

JEL Code: L60, C21, F14.

Keywords: intra-industry spillovers, inter-industry spillovers, productivity, spatial econometrics, research and development.

\author{
Harald Badinger \\ Europe Institute \\ Department of Economics \\ Vienna University of Economics and \\ Business Administration \\ Althanstr. $39-45$ \\ 1090 Vienna \\ Austria \\ Harald.Badinger@wu-wien.ac.at
}

\author{
Peter Egger \\ Center for Economic Studies \\ at the University of Munich \\ Schackstr. 4 \\ 80539 Munich \\ Germany \\ egger@ifo.de
}

December 2007

Harald Badinger currently: Research Fellow, Center for Economics Studies.

Financial support by the Austrian Science Fund (Erwin-Schrödinger-Research Fellowship) is gratefully acknowledged. 
"the transmission of technological change may also take the form of a circular process. Under such a configuration technological improvements have a magnified impact. ... All these repercussions - vertical or triangular - form part of a response mechanism that contributes to technological advancement” (Balassa, 1961, p. 150)

\section{Introduction}

The process of economic integration after World War II has markedly intensified the interdependence of economic systems at all levels of aggregation - among firms, industries, regions, and even countries. The removal of barriers to transport and trade, improvements of infrastructure facilities, better availability of high-quality information and communication technologies, and access to new modes of specialization have induced sizeable growth in trade in final goods, foreign direct investment, and trade in components and intermediate goods (also referred to as outsourcing). This increase in economic interdependence is widely believed to have indirectly triggered productivity effects. Moreover, the mentioned modes of interaction have not only likely caused such productivity effects but also rendered their impact more global in nature: We suspect that - in a strongly integrated economic environment - productivity shocks, negative or positive ones, spill over more intensively to other elements of the economic system both nationally as well as internationally.

The international economics literature on productivity spillovers roots in the seminal paper by Coe and Helpman (1995), which started off a growing literature assessing the magnitude and transmission channels of such spillovers (see Keller, 2004). While spillovers take place at various levels - among firms, industries, regions, and countries - the vast majority of previous work focuses on spillovers in a narrow, geographical sense, i.e., crossborder spillovers among regional or national entities. A much smaller number of studies considers spillovers between firms or industries. For instance, Smarzynska Javorcik (2004) and Görg, Hijzen, and Murakozy (2006) investigate the role of spillovers among firms associated with linkage effects that take place in a certain geographical neighborhood. There are hardly any studies on productivity spillovers across industries. One notable exception is Keller (2002) who considers knowledge spillovers between manufacturing industries of 8 major OECD countries over the period 1970-1991. ${ }^{1}$

The present paper investigates the role of intra- and inter-industry productivity spillovers within and among 13 OECD countries and 15 manufacturing industries. It goes beyond previous studies by considering not only knowledge spillovers (associated with research and development, henceforth referred to as R\&D) but also other types of productivity spillovers. The latter are modeled by using a spatial econometric approach. We specify spillover effects as a decreasing function of economic (rather than merely geographical) distance, which we measure by using information on the domestic and international use and delivery of intermediate goods between industries. ${ }^{2}$ Hence, our approach is inspired by

${ }^{1}$ A comprehensive survey of more than hundred empirical studies on economic growth with an emphasis on spillover effects, using conventional or spatial econometric techniques, is given by Abreu, De Groot, and Florax (2005). Strikingly, none of the studies included in the survey has used industry data.

${ }^{2}$ We put great effort into constructing an input-output matrix across countries and industries for the OECD. This comprehensive data-set on both domestic and international intra- and inter-industry use of products enables novel insights into productivity spillovers. However, due to the limited availability of internationally comparable input-output data, the focus 
Balassa's (1961) view on horizontal and vertical linkages between industries as a key source of productivity spillovers and findings of Smarzynska Javorcik (2004) at the firm level that linkage effects related to input-output relations entail an important channel of spillovers. The novelty of the paper is to allow for, distinguish, and estimate the relative importance of two different channels of total factor productivity spillovers, namely intra- versus inter-industry spillovers. As a workhorse model, we use a translog primary production function which accounts for domestic as well as imported R\&D, following Coe and Helpman (1995) in the latter regard.

As for the estimation approach, we consider a framework suitable for the analysis of cross-sectional interdependence of the units of observation. We adopt a generalized moments (GM) approach for 'spatially dependent' data by Kelejian and Prucha (2007), which is robust to heteroskedasticity. Since we aim at distinguishing between intra- and inter-industry spillovers, we extend the set of moment conditions given in Kelejian and Prucha (2007) to cope with two spillover channels and parameters of interdependence rather than a single one. We also provide evidence from a Monte Carlo analysis that this extension of Kelejian and Prucha's estimation procedure performs well, also in reasonably small samples and for heteroskedastic or homoskedastic disturbances.

Our empirical results suggest the following conclusions. First, there are sizeable knowledge spillover effects on productivity, both vertically (inter-industry) and horizontally (intra-industry). Second, stochastic productivity shocks unrelated to R\&D are significantly transmitted through input-output relationships, but mainly between similar industries. As a result, productivity shocks are magnified through intra-industry spillovers and the associated repercussions.

The remainder of this paper is organized as follows. Section II lays out the basic empirical model. Section III outlines the spatial econometric approach to modeling and estimating productivity spillovers with two rather than a single transmission channel. (The detailed extension of the GM estimator by Kelejian and Prucha (2007) and the Monte Carlo results are relegated to an Appendix.) Section IV presents the estimation results for our crosssection of 13 OECD countries and 15 manufacturing industries. Section V summarizes the main findings and concludes.

\section{The Empirical Model}

Point of departure is a standard translog production function with Hicks-neutral technological progress and two primary factors of production, labor and capital. An advantage of the translog form is its greater flexibility as compared to Cobb-Douglas or, more generally, a constant elasticity of transformation (CET) technology. It may also account for the variation in production functions across industries, since the first derivatives vary by observation. Thereby, it also mitigates endogeneity problems involved in estimating production functions (see Mahmut and Morrison Paul, 2007). ${ }^{3}$ The assumed production technology reads as follows:

has to be on the cross-sectional rather than the time-series variation in the data (i.e., on long-run relationships).

3

Given the absence of strong and convincing instruments for conditional factor demands, this is particularly important in our cross-section analysis, which precludes the use time lags as instruments unlike as with panel data (see Cohen and Morrison Paul, 2004). 


$$
\ln Y_{i k}=\ln A_{i k}+\beta_{1} \ln L_{i k}+\beta_{2} \ln K_{i k}+\beta_{3} \frac{1}{2} \ln ^{2} L_{i k}+\beta_{4} \frac{1}{2} \ln ^{2} K_{i k}+\beta_{5} \ln L_{i k} \ln K_{i k}
$$

where $Y$ is value added in real terms, $L$ is labor input, $K$ is the capital stock, and $A$ is total factor productivity. The sample comprises $i=1, \ldots, 13$ OECD countries and $k=1, \ldots, 15$ manufacturing industries, yielding 195 observations. A detailed list of the available countries and industries is given in Appendix A1.

Our main goal is to model and estimate productivity spillovers as determinants of total factor productivity $A$ and to consider whether such spillovers take place only between or within similar industries (intra-industry spillovers) or also between different types of industries (inter-industry spillovers). In particular, we model total factor productivity $A$ the following way:

$$
\ln A_{i k}=\alpha_{i}+\delta_{1} \ln R D_{i k}+\delta_{2} R D_{i k}^{*}+u_{i k}
$$

where $\alpha_{i}$ denotes a country-specific fixed effect, which captures differences in the level of development across economies, $R D_{i k}$ is 'own' research and development (R\&D) of country i's industry $k, R D_{i k}^{*}$ captures the contributions to productivity of country $i$ 's industry $k$ from R\&D in other (both domestic and foreign) industries, and $u_{i k}$ is a stochastic term, which will be talked about in greater detail below. Adopting the convention used in previous studies, the spillover term $R D_{i k}^{*}$ will be constructed as import-share weighted average of all other industries’ R\&D (see Section III).

Inserting equation (2) in (1), the full model may be written as

$$
\begin{aligned}
\ln Y_{i k}= & \alpha_{i}+\beta_{1} \ln L_{i k}+\beta_{2} \ln K_{i k}+\beta_{3} \frac{1}{2} \ln ^{2} L_{i k}+\beta_{4} \frac{1}{2} \ln ^{2} K_{i k}+\beta_{5} \ln L_{i k} \ln K_{i k}+ \\
& +\delta_{1} \ln R D_{i k}+\delta_{2} R D_{i k}^{*}+u_{i k} .
\end{aligned}
$$

We do not expect the variable $R D_{i k}^{*}$ to capture all possible spillover effects; on the one hand it captures only private and business enterprise $R \& D$ and does not account for knowledge spillovers related to public research. In addition, there are other types of intra- and inter industry effects which are not or only indirectly related to knowledge transmitted through the use of intermediate goods. An early discussion of such external economies across industries, including historical examples, is given by Balassa (1961, chapter 7). One example is that output price-reducing innovations in one industry will also increase demand for goods from input-producing industries, allowing firms in those industries to exploit economies of scale. More generally, Balassa (1961, p. 150) points out that "the transmission of technological change may also take the form of a circular process [between industries]. Under such a configuration technological improvements have a magnified impact. ... All these repercussions - vertical or triangular - form part of a response mechanism that contributes to technological advancement as the economy grows."

As a result, part of the spillovers in our model will be reflected in the $n \times 1$ error term vector $\mathbf{u}=\left[u_{i k}\right]$, where $n=195$ is the number of observations in the sample. ${ }^{4}$ In econometric

\footnotetext{
${ }^{4}$ We use the convention that bold figures indicate vectors or matrices.
} 
terms, the error term is expected to exhibit 'spatial' correlation (i.e., interdependence across units of observations), which we will talk about in more detail in the subsequent section. In matrix form, the full model reads

$$
\mathbf{y}=\mathbf{Z}_{\alpha} \alpha+\mathbf{X} \beta+\mathbf{R D} \delta+\mathbf{u}=\mathbf{Z} \gamma+\mathbf{u}
$$

The vector $\mathbf{y}$ is defined as $\mathbf{y} \equiv\left[\ln y_{i k}\right], \mathbf{Z}_{\alpha}$ is an $n \times 13$ selector (or dummy variable) matrix, $\alpha$ is a $13 \times 1$ parameter vector containing the country-specific effects, $\mathbf{R D} \equiv$ [rd $\mathbf{r d}^{*}$ ] consists of the R\&D-related parts of total factor productivity with $\mathbf{r d}=\left[\ln R D_{i k}\right]$ and $\mathbf{r d} \mathbf{d}^{*}=$ $\left[R D_{i k}^{*}\right]$, and $\mathbf{X} \equiv\left[\mathbf{l} \mathbf{k} \mathbf{l}^{2} \mathbf{k}^{\mathbf{2}} \mathbf{l k}\right]$ is the matrix collecting the respective parts of the translog production technology in equation (3), i.e., $\mathbf{l}=\left[\ln L_{i k}\right], \mathbf{k}=\left[\ln K_{i k}\right], \mathbf{l}^{2}=\left[\frac{1}{2} \ln ^{2} L_{i k}\right], \mathbf{k}^{2}=$ $\left[\frac{1}{2} \ln ^{2} K_{i k}\right]$, and $\mathbf{l k}=\left[\ln L_{i k} \ln K_{i k}\right]$. Hence, the full $n \times 20$ regressor matrix is defined as $\mathbf{Z}=$ $\left[\mathbf{Z}_{\alpha} \mathbf{X} \mathbf{R D}\right]$ and the corresponding $20 \times 1$ parameter vector is $\gamma=[\alpha \beta \delta]^{\prime}$.

\section{Modeling Intra- and Inter-Industry Productivity Spillovers: A Spatial Econometric Perspective}

\section{General Remarks}

With cross-sectional data, it is infeasible to estimate the $n \times n$ matrix of interdependence parameters for all observations in the model. But rather, it is necessary to adopt an assumption about the channel(s) and the structure of interdependence, captured by an observable $n \times n$ ('spatial weights') matrix commonly referred to as W (see Anselin, 1988, Kelejian and Prucha, 1999). For instance, in a so-called first-order spatial autoregressive residuals model (SAR1), the residual vector would be defined as $\mathbf{u}=\rho \mathbf{W u}+\varepsilon$, where $\rho$ is an unknown interdependence parameter which needs to be estimated, and $\varepsilon$ is an $n \times 1$ vector of remainder disturbances. ${ }^{5}$ As a consequence, we may write the error process as $\mathbf{u}=(\mathbf{I}-\rho \mathbf{W})^{-1} \boldsymbol{\varepsilon}$, where $\mathbf{I}$ refers to the $n \times n$ identity matrix. Using a Leontief expansion of the form $(\mathbf{I}-\rho \mathbf{W})^{-1}=\mathbf{I}+\rho \mathbf{W}+\rho^{2} \mathbf{W}^{2}+\rho^{3} \mathbf{W}^{3}+\ldots$, it is readily seen that the complete structure of the variance-covariance matrix of $\mathbf{u}, \mathrm{E}\left(\mathbf{u} \mathbf{u}^{\prime}\right)$, yields a sum of terms containing the matrix powers of $\mathbf{I}$ and $\mathbf{W}$, scaled by powers of the parameter $\rho$. Hence, the pattern of interdependence between the cross-sectional units may be viewed as an equilibrium outcome of a process that follows from 'global spatial correlation', where every unit is related to every other one through the weights matrix W (see Anselin, 2003).

Of course, the same argument applies to higher-order SAR processes, $\mathbf{u}=\left(\mathbf{I}-\sum_{k=1}^{K} \rho \mathbf{W}\right)^{-1} \varepsilon$, where $K$ denotes the order of the process. Since we will allow for both intra- and inter-industry spillovers, assuming spillovers to be global in nature seems natural. That is, we hypothesize that productivity shocks in one industry will be transmitted to all other industries, where the impact depends on the interaction intensity among the industries and countries as captured by the weights matrix.

\footnotetext{
This process is referred to as 'first order', since it only involves a single 'spatial lag',
} namely $\mathbf{W u}$. 
Notice that equation (4) may be interpreted as a restricted version of a more general model, which includes the 'spatially' weighted dependent variable (Wy) on the right-handside. Models with spatial interdependence (e.g., channeled through input-output relationships) in both the error term and the dependent variable are referred to as SARAR models. However, with our data at hand, it turns out that a SAR model (without Wy on the right-hand-side) is preferable as compared to its SARAR counterpart, according to a series of specification tests (see subsection 2 in section IV).

\section{Specification of the Weights Matrix W}

In most applications, a first-order process is assumed and the elements of the weights matrix are specified as some decreasing function of geographical distance or as function of adjacency. With two-dimensional data such as ours (exhibiting country and industry variation), using a geographical spillover channel would unnecessarily restrict spillovers to occur in the country dimension but not across industries. Inspired by Balassa (1961) and Smarzynska Javorcik (2004), we pursue an approach which relies on intermediate goods use within and across both industries and countries. Productivity spillovers, which are the subject of this study, are supposed to take place mainly among firms. Since a large share of inter-firm trade is in intermediate goods, input-output data appear to be a suitable (and feasible) choice to measure the extent and intensity of interactions both within and across industries. Such a measure of interdependence naturally spans both dimensions of our data, namely industries and countries.

However, we are not the first to use input-output-based data to model inter-industrial interdependence. Moretti (2004) investigates the effects of human capital spillovers on productivity and wages using US plant level data over the period 1982 to 1992, using rank indices based on the value of input output flows. He allows for industry-specific parameter estimates, to test whether human capital spillovers decrease with an industry's economic 'distance' (captured by smaller levels of input-output flows) from manufacturing. An important difference to our study is that Moretti rules out cross-country spillovers and focuses on a single channel (inter-industry) rather than two channels (intra- versus inter-industry) of interdependence. Keller (2002) also uses input-output data to construct knowledge spillover variables in his investigation of R\&D spillovers between manufacturing industries of 8 major OECD countries. Our study goes beyond that of Keller by considering not only knowledge spillovers in the systematic part of the model, i.e., equation (4) but also other types of spillovers captured in the disturbance term $\mathbf{u}$, which we account for by using a spatial econometric approach.

To construct the matrix of interdependence (the 'spatial weights' matrix), we use the production share of trade in intermediate goods. Specifically, we define the elements of the (unnormalized) weights matrix $\mathbf{W}^{\mathbf{0}}=\left[w_{i k, j l}^{0}\right]$ as:

$$
w_{i k, j l}^{0}=\frac{I O_{i k, j l}}{P R O D_{i k}} .
$$

The numerator $I O_{i k, j l}$ denotes exchange of intermediate goods between country $i$ 's industry $k$

\footnotetext{
${ }^{6}$ Notice that, for instance, using total international trade flows at the industry level would not entertain this feature, and would rule out spillovers across industrial boundaries.
} 
and country j's industry $l$. We consider three alternative measures of input-output flows: use, delivery, and use-plus-delivery of intermediate goods.

$I O_{i k, j l}$ in (5) is constructed as follows. Domestic input-output flows by between industries are available from the OECD's input-output database. International input-output flows are only available at a gross basis (total imported intermediates by industry for each importer-country and industry-pair). Accordingly, we have to adopt an assumption about the pattern of international trade in intermediate goods. We follow various examples in the literature by assuming that the foreign trade pattern of intermediate goods in a particular industry is similar to that of total trade. (See Appendix A1 for details.)

The denominator in equation (5), $P R O D_{i k}$, equals production (gross output) of country $i$ 's industry $k$. Hence, the corresponding weights matrix models the magnitude of the interactions between two industries by the intensity of the use (or delivery) of intermediate goods in terms of the respective industry's size.

For technical reasons and to avoid the possible singularity of $\left(\mathbf{I}-\phi \mathbf{W}^{0}\right)$, the elements of the weights matrix are typically normalized. Two normalizations are widely used. Under maximum (row or column sum) normalization the weights matrix $\mathbf{W}^{\mathbf{m n}}=\left[w_{i k, j l}^{m n}\right]$ is obtained by dividing each element of $\mathbf{W}^{\mathbf{0}}$ by the maximum row or column sum of $\mathbf{W}^{\mathbf{0}}$ (see Kelejian and Prucha, 2007, p. 9):

$$
\mathbf{W}^{\mathbf{m n}}=\left[w_{i k, j l}^{m n}\right]=\left[\frac{w_{i k, j l}^{0}}{\min \left[\max _{i k} \sum_{j l}\left|w_{i k, j l}^{0}\right|, \max _{j l} \sum_{i k}\left|w_{i k, j l}^{0}\right|\right]}\right] .
$$

We refer to the normalization in (9) as maximum-normalization in the sequel. The individually row-normalized weights matrix $\mathbf{W}^{\text {in }}=\left[w_{i k, j l}^{i n}\right]$ is obtained by dividing each element of $\mathbf{W}^{\mathbf{0}}$ by the corresponding row sum, such that the elements in each row sum up to one: ${ }^{9}$

$$
\mathbf{W}^{\mathrm{in}}=\left[w_{i k, j l}^{i n}\right]=\left[\frac{w_{i k, j l}^{0}}{\sum_{j l} w_{i k, j l}^{0}}\right] .
$$

\footnotetext{
${ }^{7}$ A similar approach is used by Feenstra and Hanson (1999), who combine data on imports of final goods with data on total input purchases, to obtain a breakdown of imported intermediate inputs by industry for US data. Bergstrand and Egger (2007) provide evidence that at least aggregate trade among the OECD countries in intermediate goods behaves remarkably similar to final goods trade.

${ }^{8}$ Notice that this is a normalization by a scalar, since the maximum row (column) sum is identical for all elements of $\mathbf{W}$.

${ }^{9}$ This is a normalization by a vector, since row sums vary across the rows of $\mathbf{W}$.
} 
Kelejian and Prucha (2007) advocate using the maximum-normalization for economic reasons. Its advantage is that, if the original matrix is symmetric, it remains so and its economic interpretation is unaffected. Technically, the choice of the maximum-normalization ensures the existence of a single rescaling factor for the interdependence parameter that leads to a specification that is equivalent to that corresponding to the model with the unnormalized weights matrix. But this approach has also drawbacks. If there is a large difference between the average and the maximum row sum, maximum-normalization may lead to an excessive downscaling of all elements in the weights matrix and, in turn, to an excessively large estimate of the interdependence parameter. This is what happens in some of our models, where the use of a maximum-normalized weights matrix in the spatial regressive error process leads to parameter estimates outside the admissible parameter range. This is not the case here if a row-normalized weights matrix is used instead.

One contribution of this paper is to assess whether there are differences between intraand inter-industry spillovers. This will be achieved by splitting up the unnormalized weights matrix $\mathbf{W}^{\mathbf{0}}$ into two components, $\mathbf{W}_{\text {intra }}^{\mathbf{0}}$ and $\mathbf{W}_{\text {inter }}^{\mathbf{0}}$. The elements of $\mathbf{W}_{\text {intra }}^{\mathbf{0}}$ correspond to that of the $n \times n$ weights matrix $\mathbf{W}^{\mathbf{0}}$ for intra-industry relations, i.e., $w_{i k, j l \text {, intra }}^{\mathbf{0}}=w_{i k, j l}^{\mathbf{0}}$ for $k=l$ and 0 otherwise. $\mathbf{W}_{\text {inter }}^{\mathbf{0}}$ reflects the elements of the $n \times n$ weights matrix $\mathbf{W}^{\mathbf{0}}$ for inter-industry relations, i.e., $w_{i k, j l, \text { inter }}^{\mathbf{0}}=w_{i k, j l}^{\mathbf{0}}$ for $k \neq l$ and 0 otherwise. It holds that $\mathbf{W}_{\mathrm{intra}}^{\mathbf{0}}+\mathbf{W}_{\mathrm{inter}}^{\mathbf{0}}=\mathbf{W}^{\mathbf{0}}$.

Under maximum-normalization the final weights matrices $\mathbf{W}_{\text {intra }}^{\mathbf{m n}}$ and $\mathbf{W}_{\text {inter }}^{\mathbf{m n}}$ are then obtained by dividing each unnormalized matrix $\mathbf{W}_{\text {intra }}^{\mathbf{0}}$ and $\mathbf{W}_{\text {inter }}^{\mathbf{0}}$ by their respective maximum row sum. Under individual row-normalization, the final weights matrices $\mathbf{W}_{\text {intra }}^{\text {in }}$ and $\mathbf{W}_{\text {inter }}^{\text {in }}$ are obtained by (separately) row-normalizing $\mathbf{W}_{\text {intra }}^{\mathbf{0}}$ and $\mathbf{W}_{\text {inter }}^{\mathbf{0}}$, i.e., dividing each row of each matrix by the respective row sum. Hence, all row sums of both $\mathbf{W}_{\text {intra }}^{\text {in }}$ and $\mathbf{W}_{\text {inter }}^{\text {in }}$ are equal to one. This is in line with the approach by Lee and Xiaodong (2006), who considers a higher order spatial autoregressive model.

We emphasize that the distinction drawn between intra- and inter-industry spillovers depends on the level of disaggregation. In the present paper, the choice of 15 fairly highly aggregated manufacturing industries (see Appendix A1) is dictated by the high level of industry aggregation in internationally comparable input-output matrices. These 15 industries are clearly heterogeneous enough to regard any cross-industrial relationship to be of the 'inter-industry' type. However, one could argue that each of these industries is made up of sub-sectors that are distinct enough from each other to regard their relationships as 'interindustrial' among similar industries. Hence, the figures about intra-industry spillovers should be interpreted as an upper bound, capturing true intra-industry spillovers as well as interindustry spillovers among fairly similar industries.

\section{R\&D Spillovers}

Our approach to modeling R\&D spillovers is closely related to that of Coe and Helpman (1995). They use (macro-economic) data from 21 OECD countries and Israel over the period 1971 to 1990 to estimate the contributions of the domestic knowledge capital stock and (bilateral import share weighted) foreign knowledge stocks to total factor productivity. A large number of studies has extended and econometrically refined this seminal procedure by Coe and Helpman (1995). (See Keller (2004) for a survey of the literature.) 
The empirical model by Coe and Helpman (1995) is closely related to a spatial econometric framework. Their R\&D spillover variable (the import share weighted foreign knowledge stock) can be interpreted as a 'spatial lag' of the vector of R\&D stocks. The weights matrix, reflecting the share of bilateral imports in total imports, can be thought of as a row-normalized weights matrix based on import flows.

To account not only for the relative but also the absolute size of imports, Coe and Helpman (1995) use an alternative specification, where (the log of) each country's importshare weighted foreign knowledge stocks is multiplied by the respective country's import share in GDP. A similar specification is chosen here. We calculate the R\&D spillover term $\left(\mathbf{r d}^{*}\right)$ as spatial lag of $\mathbf{r d}=\left[\ln R D_{i k}\right]$, using an unnormalized ${ }^{10}$ weights matrix based on the use of intermediate goods, i.e., $\mathbf{r d}^{*}=\mathbf{W}^{\mathbf{U}, 0} \mathbf{r d}$, where the elements $w_{i k, j l}^{0}$ of the weights matrix $\mathbf{W}^{\mathbf{M}, \mathbf{0}}$ are defined as the use of intermediate goods (indicated by superscript $U$ ) of country $i$ 's industry $k$ from country $j$ 's industry $l$, expressed as a share of the production of country i's industry $k$. Hence, in matrix form equation (2) reads

$$
\mathbf{A}=\boldsymbol{\alpha}+\delta_{1} \mathbf{r d}+\delta_{2} \mathbf{W}^{\mathbf{U}, 0} \mathbf{r d}+\mathbf{u} .
$$

Consequently, the (average) productivity spillover effect of a simultaneous, uniform increase in all industries’ R\&D by one percent is equal to $\delta_{2}$ times the (average) row sum of $\mathbf{W}^{\mathbf{U}, \mathbf{0}}$.

Coe and Helpman (1995) rule out domestic (i.e., within-country) spillovers transmitted through domestic (within-country) trade or intermediate goods usage, since their focus is on international spillovers. ${ }^{11}$ Here, the availability of domestic intra-industry use of intermediate goods enables us to consider this dimension of R\&D spillovers as well. Technically, this means that the matrix $\mathbf{W}^{\mathbf{U}, \mathbf{0}}$ has non-zero diagonal elements which are defined as domestic intra-industry use of intermediates as a share of production.

The spillover term rd $^{*}$ reflects both intra-industry and inter-industry spillovers at the national and international level. A contribution of this paper is to estimate the relative strength of intra-industry versus inter-industry spillovers. For this, we split up the matrix $\mathbf{W}^{\mathbf{U}, \mathbf{0}}$ into two components: $\mathbf{W}_{\text {intra }}^{\mathbf{U}, 0}$, reflecting intra-industry relationships (intermediate goods use) only, and $\mathbf{W}_{\text {inter }}^{\mathbf{U}, \mathbf{0}}$, reflecting inter-industry relationships only (see the discussion in subsection 2). We then calculate two R\&D spillover terms, $\mathbf{r d}_{\text {intra }}^{*}=\mathbf{W}_{\text {inter }}^{\mathrm{U}, \mathbf{0}} \mathbf{r d}$ and $\mathbf{r d}_{\text {inter }}^{*}=\mathbf{W}_{\text {intra }}^{\mathbf{U}, \mathbf{0}} \mathbf{r d}$ (where $\mathbf{r d}_{\text {intra }}^{*}+\mathbf{r d}_{\text {inter }}^{*}=\mathbf{r d}^{*}$ ) and allow their effects on total factor productivity to differ. We test the hypothesis $\delta_{2 \text {,intra }}=\delta_{2 \text {,inter }}$ in

${ }^{10}$ The use of an unnormalized weights matrix ensures that the absolute level of intermediates usage is accounted for. The weights matrix could also be normalized by any finite and nonzero scalar (such as the maximum row or column sum of the matrix), but this would imply a mere rescaling of the unnormalized matrix without consequences for inference or the magnitude of the implied effects.

${ }^{11}$ Frankel and Romer (1999) emphasize the role of domestic trade besides international trade. They specify productivity as a function of both international and domestic trade; since domestic trade is unobservable, they approximate it by country size (population and land area) in their estimation. 


$$
\mathbf{A}=\boldsymbol{\alpha}+\delta_{1} \mathbf{r d}+\delta_{2, \text { intra }} \mathbf{W}_{\text {intra }}^{\mathbf{U}, \mathbf{0}} \mathbf{r d}+\delta_{2, \text { inter }} \mathbf{W}_{\text {inter }}^{\mathbf{U}, \mathbf{0}} \mathbf{r d}+\mathbf{u}
$$

which is a more general version of equations (2) and (8).

As a final remark, notice that $\mathbf{W}_{\text {intra }}^{\mathbf{U , 0}}$ and $\mathbf{W}_{\text {inter }}^{\mathbf{U , 0}}$ capture both domestic as well as international input-output relationships. This reflects the main focus of this paper, which is to distinguish between intra- and inter-industry spillovers rather than between domestic and international ones. Hence, we implicitly restrict the parameters of domestic and international spillovers to be equal (both for intra- and inter-industry R\&D spillovers). This assumption appears to be justified for spillovers among the developed and highly integrated OECD countries. Differences in the magnitude of domestic and cross-border spillovers are mainly due to distance, trade costs, and border effects, which are reflected already in the magnitude of input-output flows (intermediate goods usage) the spillover weights matrices are based upon. Accordingly, equation (9) assumes that differences between domestic and international productivity spillovers will only materialize in potentially different magnitudes of the entries in the weights matrix. By contrast, differences between intra-industry and inter-industry spillovers are allowed to be qualitative in nature and show up in possibly different interdependence parameters.

\section{Remainder Productivity Spillovers in the Residuals}

In our application, there are (significant) productivity spillovers that work through channels other than the import of knowledge. These spillovers are reflected in the residuals. While previous studies on productivity spillovers have focused on knowledge spillovers, this paper allows for linkage effects channeled through input-output relationships which are not related to knowledge or R\&D. Such spillovers could be related to market structure, factor market characteristics and other economic fundamentals with a potential impact on total factor productivity (Balassa, 1961; Smarzynska Javorcik, 2004). The productivity effects of such 'remainder' spillovers may be captured and estimated in an econometric framework allowing for a 'spatial' regressive error process. We hypothesize that these other spillover effects could partly be related to the delivery of intermediates and use a row-normalized weights matrix based on the share of intermediate goods use $(U)$ plus delivery $(D)$ in production. Distinguishing again between intra- and inter-industry spillovers, we allow for parameter heterogeneity in the spatial regressive process of $\mathbf{u}$ :

$$
\mathbf{u}=\rho_{\text {intra }} \mathbf{W}_{\text {intra }}^{\text {UD,in }}+\rho_{\text {inter }} \mathbf{W}_{\text {inter }}^{\mathbf{U D , i n}}+\varepsilon .
$$

With the data-set employed below and an error process allowing for more than a single spillover channel as captured by two alternative spatial weights matrices and heterogeneous associated parameters of interdependence as in equation (10), the use of individual rownormalization will turn out to be more suitable than maximum-normalization. Then, what matters is another industry and country's relative (rather than the absolute) weight for a given country-industry dyad. Moreover, with row-normalization of either matrix, $\mathbf{W}_{\text {intra }}^{\text {in }}$ and $\mathbf{W}_{\text {inter }}^{\text {in }}$, the two channels of interdependence obtain the same ex-ante 'weight' in terms of their row sums in the error process, such that their relative importance is reflected in the parameter estimates of $\rho_{\text {intra }}$ and $\rho_{\text {inter }}$, respectively.

12 Under maximum-normalization, there can be a large difference in the maximum (and average) rows of the two matrices, such that - by construction - there will be a difference in the parameters which is simply due to a scaling effect and difficult to interpret. 
Regarding the model specification, the interdependence parameters $\left(\rho_{\text {intra }}, \rho_{\text {inter }}\right)$ have to be restricted to lie in the interval $0 \leq\left|\rho_{\text {intra }}\right|+\left|\rho_{\text {inter }}\right|<1$ under row-normalization and the main diagonal elements of both $\mathbf{W}_{\text {intra }}^{\text {UD,in }}$ and $\mathbf{W}_{\text {inter }}^{\text {UD,in }}$ have to be zero. As a consequence, we cannot incorporate domestic intra-industry spillovers in the spatial regressive specification of the residual $\mathbf{u}$. Accordingly, the weights matrix $\mathbf{W}_{\text {intra }}^{\text {UD, in }}$ captures only international intra-industry spillovers, whereas $\mathbf{W}_{\text {inter }}^{\text {UD,in }}$ reflects both domestic and international inter-industry spillovers.

To check the sensitivity of the results with respect to the choice of the weights matrix, we will consider three alternative specifications below: first, we use a maximum-normalized weights matrix rather than a row-normalized one; second, we employ a weights matrix which is based on delivery (rather than use-plus-delivery) of intermediate goods; finally, to address endogeneity concerns, we consider the case of a weights matrix whose elements are based upon the predicted values from a gravity-type model. (See subsection 3 in section IV and appendix A3 for details.)

Regarding estimation, two approaches dominate the literature: maximum likelihood estimation (see Anselin, 1988; Lee, 2004) and generalized method of moments estimation (Lee and Xiaodong, 2006; Kelejian and Prucha, 2007). A drawback of the maximum likelihood approach is that it is computationally cumbersome (particularly for large weights matrices) and that it is inconsistent, if the error term $\varepsilon$ exhibits (unknown) heteroskedasticity. Since heteroskedasticity indeed turns out to be pronounced in our data as we will show below, we choose the GM estimator by Kelejian and Prucha (2007) to obtain consistent estimates of the interdependence parameters. The estimation approach is briefly sketched in formal accounts in Appendix A2.1.

Kelejian and Prucha (2007) consider only one channel and parameter of interdependence. In Appendix A2.2.1, we extend their set of moment conditions to the case of a second order spatial autoregressive error process as specified in equation (10). ${ }^{13}$ While it is beyond the scope of this paper to elaborate on the asymptotic properties of the GM estimator for more than one spatial weights matrix, Appendix A2.2.2 illustrates by means of a Monte Carlo simulation study that the estimator based on the extended moment conditions performs reasonably well, even in small samples.

\section{Estimation Results}

Our estimates of the empirical models derived in section II are based on a cross-section, consisting of 13 OECD countries and 15 manufacturing industries (making a total of 195 observations) and refer (mainly) to the year 1995. Real value added is measured in 1995 prices, labor input is expressed in terms of hours worked. Due to lacking data on capital

${ }^{13}$ This approach is related to the ones of Bell and Bockstael (2000) and Cohen and Morrison Paul (2007), who also consider GM estimation of higher order spatial regressive error processes but assuming homoskedastic residuals. However, apart from technicalities, there is a conceptual difference between our approach and the ones of Bell and Bockstael (2000) and Cohen and Morrison Paul (2007): In our case, the different weights matrices refer to qualitatively different relationships - intra- versus inter-industry - among units in the sample rather than different geographical 'bands' (or gradual differences in neighborhood) there. 
stocks, we use the investment-intensity, defined as gross fixed capital formation relative to value added. Similarly, instead of the knowledge stock we employ the R\&D intensity, defined as private and business enterprise R\&D expenditures as a share of value added. ${ }^{14}$ While the use of intensities rather than stocks allows us to estimate productivity effects of knowledge and associated spillovers, the corresponding parameters need to be interpreted differently from a specification which employs (capital or R\&D) stocks. This issue will be discussed below. Appendix A1 provides a description of the sample of countries and industries as well as data sources and associated descriptive statistics of the variables in use.

\section{R\&D Spillovers}

Table 1 summarizes least squares estimates of the parameters for alternative empirical models. We first consider the results for the main equation only, i.e., the estimates of $\gamma$ in equation (4), and then turn to the error process, i.e., $\rho_{\text {intra }}$ and $\rho_{\text {inter, }}$, in equation (10). We start with the most parsimonious specification, including capital and labor only (except for country dummies, which are included in all models), ${ }^{15}$ and proceed by stepwise including the $R \& D$ variables discussed above. For comparison, column (1) shows the estimates of the CobbDouglas production function. Column (2) reports the estimates of the translog production function without any additional regressors. The nonlinear terms $\left(\ln ^{2} K, \ln ^{2} L\right.$, and $\left.\ln K \ln L\right)$ are jointly significant at 10 percent, indicating misspecification of the Cobb-Douglas model. Evaluated at the sample mean, the implied average derivatives are 0.507 with respect to the $\log$ of the investment intensity and 0.872 with respect to the log of labor, which is quite close to the estimates in column (1). Recovering the output elasticity with respect to the capital stock and labor from our estimates would require additional assumptions about the particular form of the production function. While the parameter estimates appear to be in a plausible range, ${ }^{16}$ we do no pursue this issue further here and turn to our main goal, i.e., the estimation of productivity spillovers.

${ }^{14}$ Physical and knowledge capital stock data are not available. One could approximate capital stocks by using the perpetual inventory method. But apart from introducing measurement error this would drastically reduce our sample size, since sufficiently long time series on real investment or R\&D expenditures are not available for many of the observations.

15

Including industry dummies is not feasible with the data at hand, since they are highly collinear with the covariates in the model. However, the goodness of fit increases only moderately in a model with industry dummies as compared to our more parsimonious specifications. We thus opt for the latter model and pool the constants across industries.

${ }^{16}$ For example, if we interpret the parameters using the steady-state of a neoclassical growth model - assuming a Cobb-Douglas production technology, constant returns to scale (as well as exogenous technological progress and labor growth) and imposing a parameter for the log of labor equal to unity (which is very close to our average estimate) - the output elasticity with respect to the capital stock $(\alpha)$ can be recovered from the relation $\varepsilon_{s}=\frac{\alpha}{1-\alpha}$, where $\varepsilon_{s}$ is the elasticity of output with respect to the investment-ratio. For the data at hand, this would imply that output elasticities with respect to the capital stock range from 0.32 to 0.49 , depending on the specification. The corresponding average elasticities based on the translog form are very similar. 
Table 1. Estimation Results, Least-squares Estimates of the Systematic Part of the Model and GM Estimates of the Remainder Spillover Process in the Residuals

\begin{tabular}{|c|c|c|c|c|c|c|}
\hline & (1) & (2) & (3) & $(4 a)$ & (4b) & $(4 c)$ \\
\hline $\ln L$ & $\begin{array}{l}0.900^{* * *} \\
(0.031)\end{array}$ & $\begin{array}{l}1.628^{* * *} \\
(0.334)\end{array}$ & $\begin{array}{l}1.667^{* * *} \\
(0.332)\end{array}$ & $\begin{array}{l}1.688^{* * *} \\
(0.309)\end{array}$ & as in (4a) & as in $(4 a)$ \\
\hline $\ln K$ & $\begin{array}{l}0.547^{* * *} \\
(0.069)\end{array}$ & $\begin{array}{l}2.783^{* * *} \\
(0.951)\end{array}$ & $\begin{array}{l}2.978^{* * *} \\
(0.948)\end{array}$ & $\begin{array}{l}2.321^{* * *} \\
(0.891)\end{array}$ & & \\
\hline $0.5 \ln ^{2} L$ & & $\begin{array}{l}-0.040^{*} \\
(0.022)\end{array}$ & $\begin{array}{l}-0.040^{*} \\
(0.021)\end{array}$ & $\begin{array}{l}-0.045^{* *} \\
(0.020)\end{array}$ & & \\
\hline $0.5 \ln ^{2} K$ & & $\begin{array}{l}-0.387^{*} \\
(0.204)\end{array}$ & $\begin{array}{l}-0.406^{* *} \\
(0.202)\end{array}$ & $\begin{array}{l}-0.317^{*} \\
(0.190)\end{array}$ & & \\
\hline $\ln L \ln K$ & & $\begin{array}{l}-0.099^{* *} \\
(0.050)\end{array}$ & $\begin{array}{l}-0.112^{* *} \\
(0.050)\end{array}$ & $\begin{array}{l}-0.086^{*} \\
(0.047)\end{array}$ & & \\
\hline rd & & & $\begin{array}{l}0.032^{*} \\
(0.017)\end{array}$ & $\begin{array}{l}0.043^{* *} \\
(0.018)\end{array}$ & & \\
\hline $\mathbf{W}_{\text {intra }}^{\mathbf{U}, \mathbf{0}} \mathbf{r d}$ & & & & $\begin{array}{l}0.231^{* * *} \\
(0.075)\end{array}$ & & \\
\hline $\mathbf{W}_{\text {inter }}^{\mathbf{U , 0}} \mathbf{r d}$ & & & & $\begin{array}{l}0.443^{* * *} \\
(0.082)\end{array}$ & & \\
\hline$R^{2}$ & 0.959 & 0.961 & 0.962 & 0.967 & & \\
\hline$\hat{\sigma}_{u}$ & 0.309 & 0.303 & 0.300 & 0.277 & & \\
\hline \multicolumn{7}{|c|}{ Error Process } \\
\hline $\mathbf{W}^{\mathrm{UD}, \mathrm{in}} \mathbf{u}$ & 0.568 & 0.660 & 0.634 & $0.399^{1)}$ & & \\
\hline $\mathbf{W}_{\text {intra }}^{\text {UD,in }} \mathbf{u}$ & & & & $0.534^{2)}$ & \multicolumn{2}{|c|}{0 (imposed) 0.526} \\
\hline $\mathbf{W}_{\text {inter }}^{\text {UD,in }} \mathbf{u}$ & & & & $-0.168^{2)}$ & -0.018 & 0 (imposed) \\
\hline$\hat{\sigma}_{\varepsilon}$ & 0.301 & 0.292 & 0.291 & 0.274 & 0.277 & 0.240 \\
\hline Moran’s I & $5.530^{* * *}$ & $6.172^{* * *}$ & $5.867^{* * *}$ & $4.824^{* * *}$ & $1.702^{*}$ & $7.937^{* * *}$ \\
\hline LM-Error & $6.538^{* *}$ & $9.241^{* * *}$ & $7.314^{* * *}$ & $3.417^{*}$ & 0.403 & $53.510^{* * *}$ \\
\hline LM-Error ${ }^{\mathrm{R}}$ & $3.165^{*}$ & $4.911^{* *}$ & $4.523^{* *}$ & 1.903 & 1.151 & $37.237^{* * *}$ \\
\hline LM-Lag & $5.415^{* *}$ & $6.345^{* * *}$ & $3.430^{* * *}$ & 2.123 & 0.151 & $16.709^{* * *}$ \\
\hline LM-Lag ${ }^{\mathrm{R}}$ & 2.043 & 2.015 & 0.639 & 0.609 & 0.898 & 0.436 \\
\hline Obs & 195 & 195 & 195 & 195 & 195 & 195 \\
\hline
\end{tabular}

Notes: Dependent variable is $\ln Y .{ }^{* * *},{ }^{* *},{ }^{*}$ indicate significance at 1,5 , and 10 percent. Standard errors in parenthesis. All models include country-specific fixed effects. $\hat{\sigma}_{u}$ and $\hat{\sigma}_{\varepsilon}$ are asymptotic standard errors of $\mathbf{u}$ and $\varepsilon$. Spatial correlation tests, referring to model $\mathbf{y}=$ $\phi \mathbf{W y}+\ldots+\mathbf{u}, \mathbf{u}=\rho \mathbf{W u}+\varepsilon$, are as follows. Superscript R refers to "robust". Small sample corrected Moran's I: $\mathrm{H}_{0}: \phi=0, \rho=0$; LM-Lag: $\mathrm{H}_{0}: \phi=0$ under $\rho=0$; LM-Lag ${ }^{\mathrm{R}}: \mathrm{H}_{0}: \phi=0, \rho$ unrestricted; LM-Error: $\mathrm{H}_{0}: \rho=0$ under $\phi=0$; LM-Error ${ }^{\mathrm{R}}: \mathrm{H}_{0}: \rho=0, \phi$ unrestricted (Anselin, Bera, Florax, and Yoon, 1996). ${ }^{1)}$ Estimate of $\rho$ assuming a SAR1 process (i.e., $\rho_{\text {intra }}=\rho_{\text {inter }}=$ $\rho) .{ }^{2)}$ Estimates of $\rho_{\text {intra }}$ and $\rho_{\text {inter }}$ assuming a SAR2 process as given in equation (10). 
Column (3) shows the results when including the (log of) 'own' R\&D intensity - captured by vector rd - as an additional regressor ('own' here refers to the same country and industry). The corresponding coefficient turns out to be significant at ten percent, reflecting an elasticity of 0.032 , which is below the effect obtained in previous (country) studies. ${ }^{17}$ For instance, Coe and Helpman (1995) estimate an elasticity of total factor productivity with respect to the domestic R\&D stock, ranging from 0.08 to 0.23 . In the most recent study in the tradition of Coe and Helpman (1995), Madsen (2007) finds an elasticity of 0.07 for 16 OECD countries and the post-1950 period. That we obtain a smaller estimate is not too surprising, since we use disaggregated data; we will return to this point below.

In a next step we include the R\&D spillover terms $\mathbf{r d}_{\text {intra }}^{*}=\mathbf{W}_{\text {intra }}^{\mathbf{U}, \mathbf{0}} \mathbf{r d}$ and $\mathbf{r d}_{\text {inter }}^{*}=\mathbf{W}_{\text {inter }}^{\mathbf{U}, \mathbf{0}} \mathbf{r d}$, allowing their parameters to differ as in equation (9). As can be seen from column (4a), both $\mathbf{r d} \mathbf{d}_{\text {intra }}^{*}$ and $\mathbf{r d} \mathbf{i n t e r}^{*}$ enter significantly at the one percent level. Moreover, the restriction that $\delta_{2 \text {,intra }}=\delta_{2 \text {,inter }}$ is clearly rejected. (The p-value of the corresponding F-test is 0.006.) In light of the fact that the average row sums of the weights matrices $\mathbf{W}_{\text {intra }}^{\mathbf{U}, \mathbf{0}}$ and $\mathbf{W}_{\text {inter }}^{\mathrm{U}, \mathbf{0}}$ are fairly close, the coefficients suggest that inter-industry R\&D spillovers are more important than intra-industry R\&D spillovers.

In terms of magnitude the estimates imply that a simultaneous increase in all industries' $R \& D$ (i.e., including own R\&D) by one percent induces spillover effects (both across industries as well as within the same industry) on total factor productivity by 0.108 percent ( 0.072 of which is due to inter-industry spillovers and 0.036 of which is due to intra-industry spillovers).

Turning to the effect of country i's and industry k's “own” R\&D again - i.e., the effect of a change in rd in equation (9) - we have to bear in mind that $\mathbf{W}_{\text {intra }}^{\mathbf{U}, \mathbf{0}}$ contains nonzero diagonal elements. Hence, in the notation of equation (9), the average total effect of own $\mathrm{R} \& \mathrm{D}$ on productivity is given by $\delta_{1}+\delta_{2, \text { intra }} \bar{w}_{i k=j l \text {, intra }}^{\mathrm{U}, 0}$, where $\bar{w}_{i k=j l \text {, intra }}^{\mathrm{U}, 0}$ is the average of the main diagonal elements of $\mathbf{W}_{\text {intra }}^{\mathbf{U}, \mathbf{0}}$. The interpretation is that the productivity effect of an increase in $\mathrm{R} \& \mathrm{D}$ is larger for industries, whose subsectors show stronger interdependence. Accounting for both the direct productivity effect of own R\&D $\left(\hat{\delta}_{1}\right)$ and the indirect effect of own $\mathrm{R} \& \mathrm{D}$ on productivity through spillovers within the same industry and country ( $\hat{\delta}_{2 \text {,intra }} \bar{w}_{i k=j l \text {,intra }}^{\mathrm{U}, 0}$ ), the total elasticity with respect to own R\&D turns out to be 0.069 . The effect on an industry's productivity of an increase in R\&D by one percent in all other industries that is the productivity effect due to spillovers except those taking place within the same industry and country - amounts to 0.081. This is consistent with the results by Keller (2002), who finds that an industry's own R\&D and spillovers from other industries account for some half of the total effect.

Based on our assumption that the parameters are equal for domestic and international relationships (see the discussion in subsection 2 of section III), the sums of the weights expressing domestic and international (intra- and inter-industry) relations can be used to infer the relative magnitudes of domestic versus international spillovers. With an average domestic

${ }^{17}$ Recall that the estimated elasticity with respect to the R\&D intensity does not directly measure the elasticity with respect to the knowledge stock. 
share of some 0.75 and 0.79 percent in total intra-industry and inter-industry use of intermediate goods, this implies that some three quarters of the $R \& D$ spillovers take place domestically. If we exclude spillover effects within the same industry (domestic intra-industry spillovers), domestic spillovers still account for some two thirds of all spillover effects. Again this is fairly close the estimates by Keller (2002), who finds that some 60 percent of all spillover effects stem from domestic industries.

The specification of the main equation given in column (4a) is our preferred model. The fit is satisfactory with an $R^{2}$ of 0.967 and a standard error of 0.277 . We now turn to a discussion of the results regarding the spatial regressive error process of $\mathbf{u}$.

\section{Remainder Productivity Spillovers}

The lower panel of Table 1 reports the Moran's I test for spatial correlation in $\mathbf{u}$ and a series of LM tests suggested by Anselin, Bera, Florax, and Yoon (1996) for specification search with spatial econometric models. For the data at hand, the results unambiguously point to the importance of spatial autocorrelation in the error term but not the dependent variable in all models. It should be noted, however, that the LM tests assume that the error term $\varepsilon$ is homoskedastic and, for the most part, that there is only a single mode of interdependence (i.e., first-order spatial correlation). Since some of our models include a second-order spatial regressive error process and heteroskedasticity in $\varepsilon$ turns out to be pronounced in our sample, ${ }^{18}$ the test statistics should only be regarded as indicative of spatial correlation in the residuals, i.e., further productivity spillovers transmitted through input-output relationships but unrelated to R\&D.

In columns (1)-(4a), we report the interdependence coefficient when assuming a firstorder SAR structure of the error process (i.e., $\rho_{\text {intra }}=\rho_{\text {inter }}=\rho$ ). In these cases, we assume that the error process is represented by $\mathbf{u}=\rho \mathbf{W}^{\mathbf{U D} \text {,in }}+\varepsilon$ rather than the second-order process reflected in equation (10). The parameter $\rho$ is estimated under the presumption of heteroskedasticity in $\varepsilon$, following Kelejian and Prucha (2007; see Appendix A2.1 for details).

In our preferred specification in column (4a), the estimate of $\rho$ is approximately 0.399 . This is supportive of the arguments by Balassa (1961) that technological improvements have a magnified impact on productivity. The coefficient suggests that a productivity shock in one industry is amplified by a factor of 1.664 in the long-run, accounting for spillovers to other industries and their repercussions. A comparison of column (3) with column (4a) in Table 1 indicates that $\rho$ declines in response to the inclusion of the R\&D spillover terms in the main equation. Hence, part - yet not all - of the interdependence across countries and industries identified in columns (1)-(3) is due to $R \& D$ spillovers channeled through national and international input-output relationships.

Using the specification in column (4a), we now take a closer look at remainder productivity spillovers as captured in the residuals. The corresponding analysis is based on the least squares residuals of the model in column (4a) and summarized in columns (4a)-(4c) in Table 1 . We first allow the spatial autoregressive parameter to vary between intra- and interindustry relations as in equation (10). For estimation, we use the extended set of moment conditions for $\rho_{\text {intra }}$ and $\rho_{\text {inter }}$ as derived in Appendix A2.2. Both weights matrices in the

${ }^{18}$ A Breusch-Pagan test rejects the null hypothesis of homoskedasticity of the error term $\varepsilon$ at one percent in all models. 
residual term are row-normalized as outlined in Section III. The estimates of $\rho_{\text {intra }}$ and $\rho_{\text {inter }}$ are reported in Table (4a) right below the results for the model, which assumes that $\rho_{\text {intra }}=$ $\rho_{\text {inter }}=\rho$. (Results for the systematic part of the model, i.e., the main equation, are the same.) Compared with the estimate for one common $\rho$, the coefficient $\rho_{\text {intra }}$ (measuring productivity effects transmitted through international intra-industry use of intermediate goods) is higher, while that of $\rho_{\text {inter }}$ (measuring productivity effects transmitted through both domestic and international inter-industry use of intermediates) turns slightly negative, according to the center panel of column (4a).

We regard the negative estimate and the small absolute value of $\rho_{\text {inter }}$ as an indication for the negligible importance of remainder inter-industry spillovers (i.e., ones beyond those embodied in R\&D). This conclusion is also supported by our Monte Carlo evidence in Appendix A2.2.2, which suggests that, in small samples, estimates of the interdependence parameters that are close to zero tend to be somewhat downward biased.

Our interpretation of the role of intra- versus inter-industry interdependence is also supported by the results from two alternative specifications of the error process, which exclude $\mathbf{W}_{\text {intra }}^{\text {UD,in }} \mathbf{u}$ and, alternatively, $\mathbf{W}_{\text {inter }}^{\text {UD,in }} \mathbf{u}$ in columns (4b) and (4c), respectively. If only inter-industry spillovers are allowed as in column (4b), where $\rho_{\text {intra }}=0$ is assumed, the estimate of $\rho_{\text {inter }}$ is again negative and tests for spatial autocorrelation in the residuals are all insignificant at five percent. ${ }^{19}$ In contrast, if only intra-industry spillovers are allowed as in column (4c), where $\rho_{\text {inter }}=0$ is assumed, the estimate of $\rho_{\text {intra }}$ increases relative to the benchmark estimates in column (4a) and all tests reject the null hypothesis of zero spatial autocorrelation. As expected from the previous results, the coefficient of $\mathbf{W}_{\text {intra }}^{\text {UD, in }} \mathbf{u}$ in column (4c) is larger than in the model, where $\rho_{\text {intra }}$ and $\rho_{\text {inter }}$ are restricted to be equal in column (4a).

Hence, our analysis of nested spillover effects suggests that there are no inter-industry spillovers associated with the stochastic part of total factor productivity. Accordingly, we proceed with a restricted version of the error process, setting $\rho_{\text {inter }}=0$. This model corresponds to the one in column (4c), and the estimate of $\rho_{\text {intra }}$ implies that a remainder productivity shock is amplified roughly by a factor of two in the long run through spillovers to similar industries (both domestic and foreign) and the associated repercussions.

\section{Feasible GLS Estimates and Sensitivity Analysis}

Having determined the preferred specification of the error process, we can improve the efficiency of the estimates of the model parameters by using a feasible generalized least squares (FGLS) approach. Kelejian and Prucha (2007, p. 22) suggest applying a standard Cochrane-Orcutt transformation to (4):

$$
\tilde{\mathbf{y}}=\tilde{\mathbf{Z}} \gamma+\tilde{\mathbf{u}}
$$

where $\tilde{\mathbf{y}}=\left(\mathbf{I}-\hat{\rho}_{\text {intra }} \mathbf{W}_{\text {intra }}^{\text {UD,in }}\right) \mathbf{y}, \widetilde{\mathbf{Z}}=\left(\mathbf{I}-\hat{\rho}_{\text {intra }} \mathbf{W}_{\text {intra }}^{\text {UD,in }}\right) \mathbf{Z}$, and $\tilde{\mathbf{u}}=\left(\mathbf{I}-\hat{\rho}_{\text {intra }} \mathbf{W}_{\text {intra }}^{\text {UD,in }}\right) \mathbf{u}=\boldsymbol{\varepsilon}$.

${ }^{19}$ This result does not depend on the normalization used and also holds up under maximumnormalization. 
Table 2. Estimation Results, Least-squares and FGLS Estimates of the Systematic Part of the Model and GM Estimates of the Remainder Spillover Process in the Residuals Using Alternative Weights Matrices

\begin{tabular}{|c|c|c|c|c|c|c|c|}
\hline & (1a) & (1b) & (2) & (3a) & (3b) & (3c) & (4) \\
\hline $\ln L$ & $\begin{array}{l}1.688^{* * *} \\
(0.339)\end{array}$ & $\begin{array}{l}1.688^{* * *} \\
(0.073)\end{array}$ & $\begin{array}{l}1.652^{* * *} \\
(0.087)\end{array}$ & $\begin{array}{l}1.765^{* * *} \\
(0.070)\end{array}$ & $\begin{array}{l}1.628^{* * *} \\
(0.100)\end{array}$ & $\begin{array}{l}1.654^{* * *} \\
(0.061)\end{array}$ & $\begin{array}{l}1.658^{* * *} \\
(0.085)\end{array}$ \\
\hline $\ln K$ & $\begin{array}{l}2.321^{* * *} \\
(0.758)\end{array}$ & $\begin{array}{l}2.110^{* * *} \\
(0.191)\end{array}$ & $\begin{array}{l}2.491^{* * *} \\
(0.227)\end{array}$ & $\begin{array}{l}2.624^{* * *} \\
(0.196)\end{array}$ & $\begin{array}{l}2.287^{* * *} \\
(0.259)\end{array}$ & $\begin{array}{l}2.261^{* * *} \\
(0.159)\end{array}$ & $\begin{array}{l}2.276^{* * *} \\
(0.246)\end{array}$ \\
\hline $0.5 \ln ^{2} L$ & $\begin{array}{l}-0.045^{*} \\
(0.024)\end{array}$ & $\begin{array}{l}-0.048^{* * *} \\
(0.005)\end{array}$ & $\begin{array}{l}-0.041^{* * *} \\
(0.006)\end{array}$ & $\begin{array}{l}-0.051^{* * *} \\
(0.005)\end{array}$ & $\begin{array}{l}-0.038^{* * *} \\
(0.007)\end{array}$ & $\begin{array}{l}-0.043^{* * *} \\
(0.005)\end{array}$ & $\begin{array}{l}-0.044^{* * *} \\
(0.006)\end{array}$ \\
\hline $0.5 \ln ^{2} K$ & $\begin{array}{l}-0.317 \\
(0.219)\end{array}$ & $\begin{array}{l}-0.320^{* * *} \\
(0.055)\end{array}$ & $\begin{array}{l}-0.356^{* * *} \\
(0.054)\end{array}$ & $\begin{array}{l}-0.412^{* * *} \\
(0.057)\end{array}$ & $\begin{array}{l}-0.281^{* * *} \\
(0.054)\end{array}$ & $\begin{array}{l}-0.333^{* * *} \\
(0.044)\end{array}$ & $\begin{array}{l}-0.322^{* * *} \\
(0.057)\end{array}$ \\
\hline $\ln L \ln K$ & $\begin{array}{l}-0.086^{* *} \\
(0.042)\end{array}$ & $\begin{array}{l}-0.069^{* * *} \\
(0.012)\end{array}$ & $\begin{array}{l}-0.091^{* * *} \\
(0.013)\end{array}$ & $\begin{array}{l}-0.090^{* * *} \\
(0.011)\end{array}$ & $\begin{array}{l}-0.090^{* * *} \\
(0.015)\end{array}$ & $\begin{array}{l}-0.078^{* * *} \\
(0.009)\end{array}$ & $\begin{array}{l}-0.080^{* * *} \\
(0.014)\end{array}$ \\
\hline rd & $\begin{array}{l}0.043^{* *} \\
(0.019)\end{array}$ & $\begin{array}{l}0.043^{* * *} \\
(0.005)\end{array}$ & $\begin{array}{l}0.051^{* * *} \\
(0.006)\end{array}$ & $\begin{array}{l}0.050^{* * *} \\
(0.006)\end{array}$ & $\begin{array}{l}0.044^{* * *} \\
(0.006)\end{array}$ & $\begin{array}{l}0.042^{* * *} \\
(0.004)\end{array}$ & $\begin{array}{l}0.046^{* * * *} \\
(0.006)\end{array}$ \\
\hline $\mathbf{W}_{\text {intra }}^{\mathrm{U}, 0} \mathbf{r d}$ & $\begin{array}{l}0.231^{* *} \\
(0.097)\end{array}$ & $\begin{array}{l}0.219^{* * *} \\
(0.019)\end{array}$ & $\begin{array}{l}0.164^{* * *} \\
(0.027)\end{array}$ & $\begin{array}{l}0.203^{* * *} \\
(0.024)\end{array}$ & $\begin{array}{l}0.186^{* * *} \\
(0.027)\end{array}$ & $\begin{array}{l}0.196^{* * *} \\
(0.018)\end{array}$ & $\begin{array}{l}0.191^{* * *} \\
(0.027)\end{array}$ \\
\hline $\mathbf{W}_{\text {inter }}^{\mathrm{U}, \mathbf{0}} \mathbf{r d}$ & $\begin{array}{l}0.443^{* * *} \\
(0.110)\end{array}$ & $\begin{array}{l}0.452^{* * *} \\
(0.032)\end{array}$ & $\begin{array}{l}0.396^{* * *} \\
(0.034)\end{array}$ & $\begin{array}{l}0.429^{* * *} \\
(0.029)\end{array}$ & $\begin{array}{l}0.398^{* * *} \\
(0.034)\end{array}$ & $\begin{array}{l}0.440^{* * *} \\
(0.025)\end{array}$ & $\begin{array}{l}0.418^{* * *} \\
(0.033)\end{array}$ \\
\hline$R^{2}$ & 0.967 & 0.967 & 0.967 & 0.967 & 0.967 & 0.967 & 0.967 \\
\hline$\hat{\sigma}_{u}$ & 0.277 & 0.278 & 0.279 & 0.279 & 0.278 & 0.278 & 0.278 \\
\hline \multicolumn{8}{|c|}{ Error Process ${ }^{1)}$} \\
\hline $\mathbf{W u}$ & 0.526 & 0.526 & 0.806 & 0.556 & & & 0.247 \\
\hline $\mathbf{W}_{\text {intra }} \mathbf{u}$ & & & 2.033 & 0.505 & \multicolumn{2}{|c|}{0 (imposed) 0.501} & 0.504 \\
\hline $\mathbf{W}_{\text {inter }} \mathbf{u}$ & & & -0.216 & -0.106 & 0.018 & 0 (imposed) & -0.120 \\
\hline$\hat{\sigma}_{\varepsilon}$ & & 0.238 & 0.277 & 0.272 & 0.278 & 0.240 & 0.277 \\
\hline Moran’s I & $7.937^{* * *}$ & $7.937^{* * *}$ & $4.147^{* * *}$ & $4.752^{* * *}$ & $2.553^{* *}$ & $7.539^{* * *}$ & $3.896^{* * *}$ \\
\hline LM-Error & $53.510^{* * *}$ & $53.510^{* * *}$ & $2.991^{*}$ & $4.451^{* *}$ & 0.000 & $48.553^{* * *}$ & 1.433 \\
\hline LM-Error $^{\mathrm{R}}$ & $37.237^{* * *}$ & $37.237^{* * *}$ & $2.855^{*}$ & $3.353^{*}$ & 0.033 & $29.509^{* * *}$ & 0.050 \\
\hline LM-Lag & $16.709^{* * *}$ & $16.709^{* * *}$ & $3.480^{*}$ & 1.423 & 2.412 & $20.834^{* * *}$ & $4.698^{* *}$ \\
\hline LM-Lag ${ }^{\mathrm{R}}$ & 0.436 & 0.436 & $3.345^{*}$ & 0.325 & 2.445 & 1.789 & $3.314^{*}$ \\
\hline Obs & 195 & 195 & 195 & 195 & 195 & 195 & 195 \\
\hline
\end{tabular}

Notes: See Table 1. Column (1a): Least squares estimates with heteroskedasticity-consistent standard errors. Columns (1b)-(4): FGLS estimates, using $\operatorname{diag}_{i=1}^{N}\left(1 / \hat{\varepsilon}_{i} \mid\right)(\mathbf{I}-\hat{\rho} \mathbf{W})$ as transformation matrix; $R^{2}$ refers to original model (generalized $R^{2}$ ). ${ }^{1)}$ Columns (1) and (1a): $\mathbf{W}=\mathbf{W}^{\text {UD,in }}$ (based on use-plus-delivery, row-normalized). Column (2): $\mathbf{W}=\mathbf{W}^{\text {UD,mn }}$ (based on use-plus-delivery, maximum-normalized). Columns (3a)-(3c): $\mathbf{W}=\mathbf{W}^{\mathbf{D} \text {,in }}$ (based on delivery, row-normalized). Column (4): $\mathbf{W}=\hat{\mathbf{W}}^{\mathbf{U D} \text {,in }}$, based on predicted values from gravity model (see Appendix A3). 
It is worth noting that this transformation suggested by Kelejian and Prucha (2007) is based on a homoskedastic error term $\varepsilon$, as assumed in Kelejian and Prucha (1999). In other words, this transformation removes heteroskedasticity in $\mathbf{u}$ induced by its spatial regressive structure, but it does not remove the heteroskedasticity of the error term $\varepsilon$ (which is pronounced in our sample). Hence, ordinary standard errors from the least squares estimation of (14) would be (still) invalid in our case.

There are two approaches to address this issue. First, heteroskedasticity-consistent standard errors rather than a GLS transformation of the (untransformed) model (4) can be used. Second, a 'full-fledged' FGLS procedure can be employed, based on a model transformation that accounts for the heteroskedasticity of $\varepsilon$ as well, using $\operatorname{diag}_{i=1}^{N}\left(1 / \hat{\varepsilon}_{i} \mid\right)\left(\mathbf{I}-\hat{\rho}_{\text {intra }} \mathbf{W}_{\text {intra }}^{\text {UD,in }}\right)$ instead of $\left(\mathbf{I}-\hat{\rho}_{\text {intra }} \mathbf{W}_{\text {intra }}^{\text {UD,in }}\right)$ as transformation matrix in equation (14).

Results for both alternatives are shown in columns (1a) and (1b) of Table 2. The use of heteroskedasticity-consistent standard errors leads to very modest changes in the standard errors with no effect on significance of the variables, see column (1a). Using a full-fledged FGLS transformation for heteroskedastic and spatially autocorrelated residuals leads to substantially lower standard errors of the parameters, see column (1b). Again, the original conclusions do not change qualitatively. In fact the least squares and the FGLS parameter estimates are very close. ${ }^{20}$ The similarity of the least-squares and the FGLS parameter estimates may be interpreted as indirect evidence that our estimates are not flawed by endogeneity of the regressors. In the absence of endogeneity, both the least-squares and the FGLS estimates are unbiased and should be similar. In the presence of endogeneity, both the least-squares and the FGLS estimates are biased but the bias is generally different for the two estimators (see Wooldridge, 2006, p. 294). Against this background, the similarity of the sets of least-squares and FGLS parameter estimates supports our specification.

Next, we infer the sensitivity of the results with respect to using alternative weights matrices for interdependence in the spatial regressive error process. Column (2) provides FGLS estimates based on a maximum-normalized weights matrix ( $\mathbf{W}^{\mathbf{U D}, \mathbf{m n}}$ ). The estimate of $\rho$ (with the restriction that $\rho_{\text {intra }}=\rho_{\text {inter }}=\rho$ ) is 0.806 . If we allow the parameters of $\mathbf{W}_{\text {intra }}^{\mathbf{U D}, \mathbf{m n}} \mathbf{u}$ and $\mathbf{W}_{\text {inter }}^{\text {UD, }} \mathbf{u}$ to differ, the estimate of $\rho_{\text {inter }}$ turns negative as it is the case in column (4a) of Table 1 with row-normalized weights. However, the estimate of $\rho_{\text {intra }}$ becomes implausibly large with a value of 2.033: For shocks occurring in several industries (with sufficiently large row sums) this would imply an unstable behavior of the remainder spillover mechanism. This result is presumably due to the fact that there is a large difference between the maximum and the average row sum of $\mathbf{W}_{\text {intra }}^{\mathbf{U D , m n}}$ (their ratio is 8.3). Since the GM estimator takes into account the average row sum, the large rescaling implied by the division through the maximum row sum leads to invalid results with maximum-normalization with the data at hand. The qualitative conclusions about the relative magnitude and the change in the parameter estimates depending on different specifications of spillovers in the stochastic part of the model, however, are consistent with the results obtained under row-normalization.

${ }^{20}$ The results for the error term are based on least squares residuals and thus identical to those in Column (4c) of Table 1.The same is true, if we use an iterative procedure; convergence is extremely fast and the associated results are de facto identical to the one-step estimates, which are reported in the Table 2. 
We next consider results obtained when using delivery rather than use-plus-delivery shares in the (row-normalized) weights matrix $\mathbf{W}^{\mathbf{D} \text {,in }}$ in columns (3a) - 3(c) of Table 2. The results shown for the main equation are the full-fledged FGLS estimates, using $\operatorname{diag}_{i=1}^{N}\left(1 /\left|\hat{\varepsilon}_{i}\right|\right)\left(\mathbf{I}-\hat{\rho}_{\text {intra }} \mathbf{W}_{\text {intra }}^{\mathbf{D}, \text { in }}\right)$ as transformation matrix in (14). The coefficients hardly differ from the FGLS estimates using $\operatorname{diag}_{i=1}^{N}\left(1 /\left|\hat{\varepsilon}_{i}\right|\right)\left(\mathbf{I}-\hat{\rho}_{\text {intra }} \mathbf{W}_{\text {intra }}^{\text {UD,in }}\right)$ as transformation matrix in (14), see column (1b). Allowing for parameter heterogeneity between $\rho_{\text {intra }}$ and $\rho_{\text {inter }}$ in the error process, we can see from column (3a) that the estimate of $\rho_{\text {inter }}$ is slightly negative, whereas the estimate of $\rho_{\text {intra }}$ is very close to that in column (1a). And as for the specification with a weights matrix based on use-plus-delivery of intermediates with $\rho_{\text {intra }}=0$, the estimate of $\rho_{\text {inter }}$ is close to zero and there is no firm evidence of significant remainder interdependence left. In contrast, when assuming $\rho_{\text {inter }}=0$, the estimate of $\rho_{\text {intra }}$ amounts to about 0.5 and all tests for spatial autocorrelation reject the null hypothesis (of zero remainder interdependence) at a high level of significance. The magnitude of the implied effect is de facto identical to that in column (1a), where the weights matrix is based on use-plus-delivery of intermediate goods. Again, this supports our view that spillovers primarily take place within the same industry or between very similar ones.

We notice that using a weights matrix based on use of intermediate goods only we find much weaker evidence for spatial correlation (which often turns out insignificant). We take the last set of results as indirect evidence that export related spillovers are important. This is in line with recent studies on that matter. Greenaway, Sousa, and Wakelin (2004) find indirect productivity spillovers through exports by multinational enterprises to domestic firms in the same industry, using UK firm level data. Alvarez and Lopez (2006), using plant-level data from Chile, find that exporting by foreign-owned plants generates positive productivity spillovers to other plants in the same industry; to a smaller extent this is also true for domestic exporters.

As a final robustness analysis, we consider the results when the use-plus-delivery based weights matrix in the error process is generated from the predicted values of a gravity model, including country-pair dummies, industry-pair dummies, and distance between countries (or internal distance for domestic use-plus-delivery intensities) as determinants of use-plusdelivery intensities across industry-country-pairs. This approach aims at avoiding the potential endogeneity of intermediate goods flows, similar to an instrumental variable model. ${ }^{21}$ Appendix A3 gives a more detailed description of the construction of the predicted weights matrix, which we refer to as $\hat{\mathbf{W}}^{\mathbf{U D} \text {,in }}$. Column 4 in Table 2 shows the results, using $\hat{\mathbf{W}}^{\text {UD,in }}$ (or, alternatively, $\hat{\mathbf{W}}_{\text {intra }}^{\text {UD,in }}$ and $\hat{\mathbf{W}}_{\text {inter }}^{\text {UD,in }}$ ) as weights matrix in the error term. Notice first that the FGLS estimates of the systematic part of the model are very close to that using the original weights matrix $\mathbf{W}^{\mathbf{U D} \text {,in }}$, see column (2) of Table 2 . For the model assuming $\rho_{\text {intra }}=$ $\rho_{\text {inter }}=\rho$, the estimate of the interdependence parameter turns out to be 0.247 ; allowing for interdependence parameter heterogeneity the estimate of $\rho_{\text {intra }}$ increases to 0.504 , whereas that of $\rho_{\text {inter }}$ becomes negative and amounts to -0.120 (see the center panel of column 4). Restricting $\rho_{\text {intra }}$ to be equal to zero, the estimate of $\rho_{\text {inter }}$ is close to zero $(0.047)$ with much

${ }^{21}$ Our approach is inspired by that of Frankel and Romer (1999), who use the country-specific sum of predicted bilateral trade flows from a 'geographical' gravity model as an instrument in a cross-country regression of per capita income on (endogenous) trade and country size. 
smaller spatial correlation test statistics, whereas restricting $\rho_{\text {inter }}$ to be equal to zero results in an estimate of $\rho_{\text {intra }}$ equal to 0.504 with highly significant spatial correlation. These findings are qualitatively and quantitatively in line with the results using the original weights matrices $\mathbf{W}_{\text {intra }}^{\text {UD,in }}$ and $\mathbf{W}_{\text {inter }}^{\text {UD,in }}$. The same holds true, if the predicted weights matrix is based on intermediated goods use or delivery intensities only (rather than the use-plus-delivery intensity).

Taking this approach one step further and using a predicted weights matrix for the construction of the R\&D spillovers terms in the main model as well, the conclusions regarding the error process are unchanged. In the systematic part of the model, however, the least squares coefficients of both $\mathbf{r d}_{\text {intra }}^{*}$ and $\mathbf{r d}_{\text {inter }}^{*}$ are reduced to -0.054 and 0.118 , where only the coefficient of $\mathbf{r d}_{\text {inter }}^{*}$ remains significant at 5 percent. The most likely explanation for this result is that the use of a predicted weights matrix (while mitigating endogeneity problems due to reverse causality and omitted variables) introduces measurement error, causing attenuation bias in the parameter estimates of $\mathbf{r d}_{\text {intra }}^{*}$ and $\mathbf{r d} \mathbf{d}_{\text {inter }}^{*}$.

\section{Conclusions}

This paper considers the productivity effects of knowledge and other type of spillovers, using a cross-section of 13 OECD countries and 15 manufacturing industries. It allows for spillovers to cross both national and industrial boundaries and pays specific attention to the relative magnitude of intra- versus inter-industry spillovers that are transmitted through inputoutput relations. We allow such spillovers to be either related to R\&D intensities or other, not further specified sources (such as product or factor market characteristics). To account for the latter, we adopt a spatial econometric approach.

Focusing on input-output relations and linkage-driven spillovers, we hypothesize that spillovers between countries and industries decline with economic (rather than merely geographical) distance, which we measure using information on the domestic and international use and delivery of intermediate goods between industries.

In our estimation of knowledge spillovers, we extend the empirical analysis by Coe and Helpman (1995) along three lines. First, we use industry rather than country data. Second, we test for differences in intra- and inter-industry spillovers related to R\&D. Third, we allow for remainder spillovers beyond those embodied in $R \& D$, which are not further specified but hypothesized to be related to input-output linkages as well. For the latter, allowing intraindustry spillovers to differ from inter-industry spillovers requires a spatially autoregressive model for residuals with two rather than a single channel of interdependence. Suitable for our dataset with cross-sectional interdependence and pronounced heteroscedasticity, we use the heteroscedasticity-robust GM estimator by Kelejian and Prucha (2007) and extend their set of moment conditions to cope with two spillover channels and parameters of interdependence (intra- and inter-industry spillovers).

The results suggest that there are sizeable knowledge spillover effects on productivity, transmitted through both inter-industry and intra-industry use of intermediate goods. The data allow us also to estimate both the direct effect of an increase in an industry's (own) R\&D, as well as the indirect productivity effect triggered by $R \& D$ spillover effects within the respective industry. This indirect effect is statistically and also economically significant, amplifying the elasticity of productivity with respect to own R\&D from 0.043 (the direct 
effect) to a total of 0.069 . The elasticity of productivity with respect to an increase in all other industries’ R\&D turns out to be 0.081 .

There is evidence of remainder spillovers which are not related to knowledge but also transmitted by input-output linkages. However, statistically significant remainder spillovers are only found within or among very similar industries; there is no evidence of inter-industry spillovers unrelated to R\&D. Shocks to total factor productivity unrelated to knowledge are amplified by roughly a factor of two through intra-industry spillovers and the associated repercussions. The results may be interpreted as evidence of an even stronger intra-industry spillover mechanism for shocks to total factor productivity which are unrelated to knowledge than for ones that are embedded in knowledge.

Apart from the finding of relatively important non-knowledge spillovers, our results indicate that spillovers do not only occur through the use of (domestic or imported) intermediate goods. Linkage effects seem to materialize through both the use and the delivery of intermediates. The latter finding indicates that specifications restricting spillovers to take place only through imports rather than exports and imports may underestimate the importance of spillovers and linkage effects as determinants of total factor productivity. 


\section{References}

Abreu, M., De Groot, H.L.F., and Florax, J.G.M. (2005). Space and growth: a survey of the empirical evidence and methods. Région et Développement, 21, 13-44.

Alvarez, R. and Lopez, R. (2006). Is exporting a source of productivity spillovers? Caepr Working Papers, No. 2006-012.

Anselin, L. (1988). Spatial Econometrics: Methods and Models. Dordrecht: Kluwer, 1988.

Anselin, L. (2003). Spatial externalities, spatial multipliers, and spatial econometrics. International Regional Science Review, 26(2), 153-166.

Anselin, L., Bera, A.K., Florax, R. and Yoon, M.J. (1996). Simple diagnostic tests for spatial dependence. Regional Science and Urban Economics, 26, 77-104.

Balassa, B. (1961). The Theory of Economic Integration. London: Allen \& Unwin.

Bell, K.P. and Bockstael, N.E. (2000). Applying the generalized-moments estimation apporoach to spatial problems involving microlevel data. The Review of Economics and Statistics, 82(1), 72-82.

Bergstrand, J.H. and Egger, P. (2007). Outsourcing: measurement, determinants, and consequences of international trade. Unpublished manuscript, University of Notre Dame.

Coe, D.T. and Helpman, E. (1995). International R\&D spillovers. European Economic Review, 39(5), 859-87.

Cohen, J.P. and Morrison Paul, C.J. (2004). Public Infrastructure investment, interstate spatial spillovers, and manufacturing costs. The Review of Economics and Statistics, 86(2), 551-560.

Cohen, J.P. and Morrison Paul, C.P. (2007). Higher order spatial autocorrelation in a system of equations: the impacts of transportation infrastructure on capital asset values. Unpublished manuscript.

Feenstra, R.C. and Hanson, G.H. (1999). The impact of outsourcing and high technology capital on wages: estimates for the United States, 1979-1990. Quarterly Journal of Economics, 114(3), 907-940.

Frankel, J.A. and Romer, D. (1999). Does trade cause growth? American Economic Review, 89(3), 279-399.

Görg, H., Hijzen, A., and Murakozy, B. (2006). The productivity spillover potential of foreign-owned firms: Firm-level evidence for Hungary. GEP Research Paper No. 2006/08, University of Nottingham.

Greenaway, D., Sousa, N., and Wakelin, K. (2004). Do domestic firms learn to export from multinationals? European Journal of Political Economy, 20(4), 1027-1043.

Kelejian, H.H. and Prucha, I.R. (1999). A generalized moments estimator for the autoregresssive parameter in a spatial model. International Economic Review, 40, 509533.

Kelejian, H.H. and Prucha, I.R. (2007). Specification and estimation of spatial autoregressive models with autoregressive and heteroskedastic disturbances. Journal of Econometrics (forthcoming).

Keller, W. (2002). Trade and the transmission of technology. Journal of Economic Growth, 7, $5-24$ 
Keller, W. (2004). International technology diffusion. Journal of Economic Literature, Vol. XLII, 752-782.

Lee, L.F. (2004). Asymptotic distribution of maximum likelihood estimators for spatial autoregressive models. Econometrica, 72, 1899-1925.

Lee, L.F. and Xiaodong, L. (2006). Efficient GMM estimation of high order spatial autoregressive models. Working paper, Department of Economics, Ohio State University.

Mahmut, Y. and Morrison Paul, C.J. (2007). International linkages and productivity at the plant: foreign direct investment, exports, imports and licensing. Journal of International Economics, 71, 373-388.

Mayer, T. and Zignago, S. (2006). Notes on CEPII's distances measures. CEPII, Paris.

Moretti, E. (2004). Workers' education, spillovers and productivity: evidence from plant level production functions. American Economic Review, 94(3), 656-690.

Santos Silva, J.M.C. and Tenreyro, S. (2006). The log of gravity. The Review of Economics and Statistics, 88(4), 641-658.

Smarzynska Javorcik, B. (2004). Does foreign direct investment increase the productivity of domestic firms? In search of spillovers through backward linkages. American Economic Review 94(3), 605-627.

Wooldridge, J. (2006). Introductory Econometrics, $3^{\text {rd }}$ edition, Mason, Ohio: South-Western. 


\section{Appendix A1. Data and Sample}

\section{A1.1 Data Sources}

Our final sample is determined by data availability and comprises 13 countries (CAN, CZE, DEU, DNK, ESP, FIN, FRA, GBR, ITA, NLD, NOR, POL, USA) and 15 industries (see below). Of the 195 observations, data on investment and $R \& D$ expenditures is missing for some countries and industries such that 170 observations remain. 20 of the 25 missing observations were imputed from higher levels of aggregation; the other missing values were approximated, using the ratio of a variable's value in the particular industry to the average value across all available industries. Data on value added (in 1995 prices) and employment (hours worked) are taken from the Groningen Growth and Development Center (GGDC). Investment data are from the OECD Structural Analysis (STAN) database. Data on R\&D expenditures are from the OECD's Analytical Business Enterprise Research and Development (ANBERD) database. The cross-section data refer to 1995, a choice dictated by the availability of input-output tables, which refer to the period around 1995. Investment- and R\&D intensities are averages over the longest available time span over the period 1990-2000. Data on distances between countries and internal distance within countries are from the CEPII database (http://www.cepii.fr/).

Input-output data to construct the weights matrix are from the OECD input-output database. International input-output flows by industry are assumed to exhibit the same bilateral trade pattern as total trade. Information on the level of imported intermediate goods (i.e., international use of intermediates) of industry $k$ from industry $l$ is combined with bilateral import shares in total imports of industry $k$. Exports of intermediate goods (i.e., international delivery of intermediates) of industry $k$ to foreign industries $l$ are assumed to be symmetric to imports of industry $l$ from foreign industries $k$ and combined with bilateral export shares in total exports in industry $k^{22}$ The shares of bilateral import and exports in total trade at the industry level are calculated from the OECD's STAN bilateral trade database.

\section{A1.2 List of Industries and Summary Statistics}

\footnotetext{
${ }^{22}$ The relevance of this approximation is reduced by the fact that all weights matrices based on delivery of intermediate goods are row-normalized; as a consequence, the more relevant assumption is that bilateral export shares in total exports are equal to bilateral shares in intermediate goods exports.
} 
Table A1. List of Industries and Summary Statistics

\begin{tabular}{|c|c|c|c|c|c|c|c|c|}
\hline & & VA/ hour & $\begin{array}{l}\text { Investment } \\
\text { intensity }\end{array}$ & $\begin{array}{c}\text { R\&D } \\
\text { intensity }\end{array}$ & $\begin{array}{l}\text { Total use of } \\
\text { intermediate } \\
\text { goods }\end{array}$ & $\begin{array}{l}\text { Inter- } \\
\text { industry use }\end{array}$ & $\begin{array}{l}\text { Domestic } \\
\text { use }\end{array}$ & $\begin{array}{l}\text { domestic } \\
\text { intra- } \\
\text { industry use }\end{array}$ \\
\hline ISIC Rev3 & Industry & \$/hour & $\begin{array}{c}\text { percent of } \\
\text { value added }\end{array}$ & $\begin{array}{l}\text { percent of } \\
\text { value added }\end{array}$ & $\begin{array}{l}\text { percent of } \\
\text { production }\end{array}$ & \multicolumn{3}{|c|}{ percent of total use } \\
\hline $15-16$ & Food products, beverages and tobacco & 30.18 & 17.89 & 1.05 & 24.24 & 31.35 & 90.35 & 63.13 \\
\hline $17-19$ & Textiles, textile products, leather and footwear & 18.64 & 10.81 & 0.83 & 29.60 & 32.38 & 82.81 & 55.85 \\
\hline 20 & Wood and products of wood and cork & 21.45 & 16.31 & 1.13 & 26.28 & 36.75 & 86.46 & 56.14 \\
\hline $21-22$ & Pulp, paper, paper products, print.and publishing & 33.09 & 19.04 & 0.55 & 32.94 & 24.43 & 82.21 & 63.05 \\
\hline 23 & Coke, refined petr. products and nuclear fuel & 73.66 & 32.38 & 1.33 & 10.93 & 41.63 & 85.45 & 50.82 \\
\hline 24 & Chemicals and chemical products & 54.01 & 21.12 & 10.47 & 30.64 & 37.49 & 70.98 & 39.41 \\
\hline 25 & Rubber and plastics products & 28.93 & 18.45 & 2.23 & 33.83 & 76.26 & 69.50 & 18.88 \\
\hline 26 & Other non-metallic mineral products & 30.47 & 19.20 & 1.21 & 22.56 & 57.47 & 83.96 & 37.40 \\
\hline 27 & Basic metals & 39.93 & 20.67 & 2.18 & 36.86 & 35.43 & 76.58 & 47.10 \\
\hline 28 & Fabricated metal products & 24.28 & 13.66 & 0.99 & 34.47 & 72.81 & 80.78 & 24.07 \\
\hline 29 & Machinery and equipment, n.e.c. & 27.84 & 11.23 & 4.51 & 36.67 & 67.15 & 75.03 & 21.73 \\
\hline $30-33$ & Electrical and optical equipment & 30.71 & 15.43 & 13.50 & 37.09 & 42.42 & 66.62 & 32.73 \\
\hline 34 & Motor vehicles, trailers and semi-trailers & 31.16 & 25.77 & 8.73 & 50.22 & 53.10 & 63.72 & 25.87 \\
\hline 35 & Other transport equipment & 26.11 & 15.11 & 15.73 & 40.84 & 65.95 & 69.42 & 19.42 \\
\hline \multirow[t]{2}{*}{$36-37$} & Manufacturing n.e.c. & 20.17 & 11.93 & 0.73 & 30.96 & 83.98 & 84.59 & 13.03 \\
\hline & Column averages & 32.71 & 17.93 & 4.34 & 31.88 & 50.57 & 77.90 & 37.91 \\
\hline
\end{tabular}

Notes: Statistics are simple country averages. VA is value added in 1995 prices, 1995 US\$. Investment intensity is share of gross fixed capital formation in value added in percent. R\&D intensity is private and business enterprise R\&D expenditures as share of value added. Use of intermediate goods corresponds to (average) row sum of unnormalized weights matrix $\mathbf{W}^{\mathbf{U}, \mathbf{0}}$ (including domestic intra-industry use). Inter-industry use corresponds to average row sum of $\mathbf{W}_{\text {inter }}^{\mathbf{U}, 0}$. Domestic use corresponds to intra- and inter-industry use from industries of the same country. Domestic intra-industry use corresponds to main diagonal elements of $\mathbf{W}^{\mathbf{U}, \mathbf{0}}$. 


\section{Appendix A2. GM Estimation of the Spatial Autoregressive Parameter $\rho$}

\section{A2.1 Moment Conditions for First Order Spatial Regressive Error Process}

Consider the model:

$$
\begin{aligned}
& \mathbf{y}=\mathbf{X} \boldsymbol{\beta}+\mathbf{u}, \\
& \mathbf{u}=\rho \mathbf{W u}+\boldsymbol{\varepsilon},
\end{aligned}
$$

where $\mathbf{X}$ is a matrix of explanatory variables and $\boldsymbol{\varepsilon}$ is a stochastic error term. Having obtained consistent estimates of $\mathbf{u}$ from the main model, the generalized moments (GM) estimator by Kelejian and Prucha (2007) can be used to estimate the spatial regressive parameter $\rho$ in equation (A1b). It is based on the following moment conditions, which rely on independently though not necessarily identically distributed disturbances $\varepsilon_{i}$ and some restrictions on the properties of the weights matrix:

$$
\begin{aligned}
& n^{-1} E\left[\bar{\varepsilon}^{\prime} \bar{\varepsilon}-\operatorname{Tr}\left\{\mathbf{W} \operatorname{diag}_{i=1}^{N}\left[\left(E \varepsilon_{i}^{2}\right)\right] \mathbf{W}^{\prime}\right\}\right]=0, \text { and } \\
& n^{-1} E \overline{\boldsymbol{\varepsilon}}^{\prime} \varepsilon=0,
\end{aligned}
$$

where $\bar{\varepsilon}=\mathbf{W} \varepsilon ; N$ is the total number of observations and $\operatorname{Tr}$ is the trace operator.

Under homoskedasticity the moment conditions simplify to (see Kelejian and Prucha (2007, p. 11):

$$
\begin{aligned}
& n^{-1} E\left[\bar{\varepsilon}^{\prime} \bar{\varepsilon}-\varepsilon^{\prime} \varepsilon n^{-1} \operatorname{Tr}\left(\mathbf{W} \mathbf{W}^{\prime}\right)\right]=0 \\
& n^{-1} E \bar{\varepsilon}^{\prime} \varepsilon=0
\end{aligned}
$$

Substituting for $\varepsilon=(\mathbf{I}-\rho \mathbf{W}) \mathbf{u}$ yields a two equation system in $\rho$ and $\rho^{2}$. Its empirical counterpart is given by:

$$
\tilde{\gamma}-\tilde{\boldsymbol{\Gamma}} \boldsymbol{\alpha}=\boldsymbol{v},
$$

where $\boldsymbol{\alpha}=\left[\rho, \rho^{2}\right]^{\prime}$ and the elements of the $2 \times 1$ vector $\tilde{\boldsymbol{\gamma}}$ and the $2 \times 2$ Matrix $\tilde{\boldsymbol{\Gamma}}$ can be calculated from the estimates of $\mathbf{u}$ and the elements of the weights matrix $\mathbf{W}$; $v$ can be regarded as a vector of regression residuals. The GM estimator of $\rho$ is now defined as weighted nonlinear least squares estimator based on (A.4). It is obtained by:

$$
\tilde{\rho}=\underset{\rho}{\operatorname{argmin}}\left[(\tilde{\boldsymbol{\gamma}}-\tilde{\boldsymbol{\Gamma}} \boldsymbol{\alpha})^{\prime} \mathbf{\Omega}(\tilde{\boldsymbol{\gamma}}-\tilde{\boldsymbol{\Gamma}} \boldsymbol{\alpha})\right]
$$

The choice of the weights matrix $\Omega$ affects only efficiency. Hence, a feasible approach to obtain a consistent estimate of $\rho$ is to use the identity matrix for $\Omega$.

\section{A2.2 Allowing for Parameter Heterogeneity in the Spatial Regressive Process}

Kelejian and Prucha (2007) consider only one homogenous parameter $\rho$ in the spatial regressive process. A more general specification allows for $M$ heterogeneous parameters in the spatial autoregressive process:

$$
\mathbf{u}=\sum_{m=1}^{M} \boldsymbol{\rho}_{m} \mathbf{W}_{m} \mathbf{u}+\boldsymbol{\varepsilon},
$$

where the matrices $\mathbf{W}_{m}$ have the same dimension as $\mathbf{W}$ in (A.1b). ${ }^{23}$

${ }^{23}$ A similar extension of the moment conditions, although for the case of homescedasticity as in Kelejian and Prucha (1999), is used by Bell and Bockstael (2000) as well as Cohen and Morrison Paul (2007). 


\section{A2.2.1 Moment Conditions for Higher Order Spatial Regressive Error Process}

The generalized GM estimator can be obtained by recognizing that - using the same assumptions as in Kelejian and Prucha (2007) - the moment conditions given by (A.3a) and (A.3b) must hold for each matrix $\mathbf{W}_{m}$ :

$$
\begin{aligned}
& n^{-1} E\left[\bar{\varepsilon}_{m}^{\prime} \bar{\varepsilon}_{m}-\operatorname{Tr}\left\{\mathbf{W}_{m} \operatorname{diag}_{i=1}^{N}\left[\left(E \varepsilon_{i}^{2}\right)\right] \mathbf{W}_{m}^{\prime}\right\}\right], \text { and } \\
& n^{-1} E \overline{\boldsymbol{\varepsilon}}_{m}^{\prime} \boldsymbol{\varepsilon}=0,
\end{aligned}
$$

where $\bar{\varepsilon}_{m}=\mathbf{W}_{m} \varepsilon$.

In the present study we consider the case of $M=2$. The spatial regressive error term then given by

$$
\mathbf{u}=\rho_{1} \mathbf{W}_{1} \mathbf{u}+\rho_{2} \mathbf{W}_{2} \mathbf{u}+\varepsilon,
$$

Allowing for heteroskedasticity in the error $\varepsilon$, the moment conditions are given by

$$
\begin{aligned}
& n^{-1} E\left[\bar{\varepsilon}_{1}^{\prime} \bar{\varepsilon}_{1}-\operatorname{Tr}\left\{\mathbf{W}_{1} \operatorname{diag}_{i=1}^{N}\left[\left(E \varepsilon_{i}^{2}\right)\right] \mathbf{W}_{1}^{\prime}\right\}\right], \\
& n^{-1} E \bar{\varepsilon}_{1}^{\prime} \varepsilon=0, \\
& n^{-1} E\left[\bar{\varepsilon}_{2}^{\prime} \bar{\varepsilon}_{2}-\operatorname{Tr}\left\{\mathbf{W}_{2} \operatorname{diag}_{i=1}^{N}\left[\left(E \varepsilon_{i}^{2}\right)\right] \mathbf{W}_{2}^{\prime}\right\}\right], \\
& n^{-1} E \bar{\varepsilon}_{2}^{\prime} \varepsilon=0,
\end{aligned}
$$

where $\bar{\varepsilon}_{1}=\mathbf{W}_{1} \varepsilon$ and $\bar{\varepsilon}_{2}=\mathbf{W}_{2} \varepsilon$.

From the specification of the error term in (A.8) it follows that

$$
\begin{aligned}
& \boldsymbol{\varepsilon}=\mathbf{u}-\rho_{1} \mathbf{W}_{1} \mathbf{u}-\rho_{2} \mathbf{W}_{2} \mathbf{u}=\mathbf{u}-\rho_{1} \overline{\mathbf{u}}_{1}-\rho_{2} \overline{\mathbf{u}}_{2} \\
& \bar{\varepsilon}_{1}=\mathbf{W}_{1} \varepsilon=\mathbf{W}_{1} \mathbf{u}-\rho_{1} \mathbf{W}_{1} \mathbf{W}_{1} \mathbf{u}-\rho_{2} \mathbf{W}_{1} \mathbf{W}_{2} \mathbf{u}=\overline{\mathbf{u}}_{1}-\rho_{1} \overline{\overline{\mathbf{u}}}_{1}-\rho_{2} \overline{\overline{\mathbf{u}}}_{12} . \\
& \overline{\boldsymbol{\varepsilon}}_{2}=\mathbf{W}_{2} \boldsymbol{\varepsilon}=\mathbf{W}_{2} \mathbf{u}-\rho_{1} \mathbf{W}_{2} \mathbf{W}_{1} \mathbf{u}-\rho_{2} \mathbf{W}_{2} \mathbf{W}_{2} \mathbf{u}=\overline{\mathbf{u}}_{2}-\rho_{1} \overline{\overline{\mathbf{u}}}_{21}-\rho_{2} \overline{\overline{\mathbf{u}}}_{2},
\end{aligned}
$$

where we use the following definitions:

$$
\overline{\mathbf{u}}_{1}=\mathbf{W}_{1} \mathbf{u}, \overline{\mathbf{u}}_{2}=\mathbf{W}_{2} \mathbf{u}, \overline{\overline{\mathbf{u}}}_{1}=\mathbf{W}_{1} \mathbf{W}_{1} \mathbf{u}, \overline{\overline{\mathbf{u}}}_{2}=\mathbf{W}_{2} \mathbf{W}_{2} \mathbf{u}, \overline{\overline{\mathbf{u}}}_{12}=\mathbf{W}_{1} \mathbf{W}_{2} \mathbf{u}, \overline{\overline{\mathbf{u}}}_{21}=\mathbf{W}_{2} \mathbf{W}_{1} \mathbf{u} .
$$

Substituting (A.11a)-(A.11c) into the moment conditions (A.9a)-(A.10b) we obtain the following four equation system:

$$
\boldsymbol{\gamma}-\boldsymbol{\Gamma} \boldsymbol{\alpha}=0,
$$

where $\boldsymbol{\alpha}=\left[\rho_{1}, \rho_{2}, \rho_{1} \rho_{2}, \rho_{1}^{2}, \rho_{2}^{2}\right]^{\prime}$ and the elements of $\gamma=\left[\gamma_{1}, \gamma_{2}, \gamma_{3}, \gamma_{4}\right]^{\prime}$ and $\Gamma=\left[\gamma_{i, j}\right]_{i=1, \ldots 4, j=1, \ldots 5}$ are given by:

$$
\begin{aligned}
& \gamma_{1}=n^{-1} E\left[\overline{\mathbf{u}}_{1}^{\prime} \overline{\mathbf{u}}_{1}-\operatorname{Tr}\left\{\mathbf{W}_{1} \operatorname{diag}_{i=1}^{N}\left[\left(E u_{i}^{2}\right)\right] \mathbf{W}_{1}^{\prime}\right\}\right] \\
& \gamma_{2}=n^{-1} E\left[\overline{\mathbf{u}}_{1}^{\prime} \mathbf{u}\right] \\
& \gamma_{3}=n^{-1} E\left[\overline{\mathbf{u}}_{2}^{\prime} \overline{\mathbf{u}}_{2}-\operatorname{Tr}\left\{\mathbf{W}_{2} \operatorname{diag}_{i=1}^{N}\left[\left(E u_{i}^{2}\right)\right] \mathbf{W}_{2}^{\prime}\right\}\right] \\
& \gamma_{4}=n^{-1} E\left[\overline{\mathbf{u}}_{2}^{\prime} \mathbf{u}\right] \\
& \gamma_{1,1}=2 n^{-1} E\left[\overline{\overline{\mathbf{u}}}_{1}^{\prime} \overline{\mathbf{u}}_{1}-\operatorname{Tr}\left\{\mathbf{W}_{1} \operatorname{diag}_{i=1}^{N}\left[\left(E \bar{u}_{1 i} u_{i}\right)\right] \mathbf{W}_{1}^{\prime}\right\}\right] \\
& \gamma_{2,1}=n^{-1} E\left[\overline{\overline{\mathbf{u}}}_{1}^{\prime} \mathbf{u}+\overline{\mathbf{u}}_{1}^{\prime} \overline{\mathbf{u}}_{1}\right] \\
& \gamma_{3,1}=2 n^{-1} E\left[\overline{\overline{\mathbf{u}}}_{21}^{\prime} \overline{\mathbf{u}}_{2}-\operatorname{Tr}\left\{\mathbf{W}_{2} \operatorname{diag}_{i=1}^{N}\left[\left(E \bar{u}_{1 i} u_{i}\right)\right] \mathbf{W}_{2}^{\prime}\right\}\right] \\
& \gamma_{4,1}=n^{-1} E\left[\overline{\overline{\mathbf{u}}}_{21}^{\prime} \mathbf{u}+\overline{\mathbf{u}}_{2}^{\prime} \overline{\mathbf{u}}_{1}\right] \\
& \gamma_{1,2}=2 n^{-1} E\left[\overline{\overline{\mathbf{u}}}_{12}^{\prime} \overline{\mathbf{u}}_{1}-\operatorname{Tr}\left\{\mathbf{W}_{1} \operatorname{diag}_{i=1}^{N}\left[\left(E \bar{u}_{2 i} u_{i}\right)\right] \mathbf{W}_{1}^{\prime}\right\}\right] \\
& \gamma_{2,2}=n^{-1} E\left[\overline{\mathbf{u}}_{1}^{\prime} \overline{\mathbf{u}}_{2}+\overline{\overline{\mathbf{u}}}_{12}^{\prime} \mathbf{u}\right] \\
& \gamma_{3,2}=2 n^{-1} E\left[\overline{\overline{\mathbf{u}}}_{2}^{\prime} \overline{\mathbf{u}}_{2}-\operatorname{Tr}\left\{\mathbf{W}_{2} \operatorname{diag}_{i=1}^{N}\left[\left(E \bar{u}_{2 i} u_{i}\right)\right] \mathbf{W}_{2}^{\prime}\right\}\right] \\
& \gamma_{4,2}=n^{-1} E\left[\overline{\overline{\mathbf{u}}}_{2}^{\prime} \mathbf{u}+\overline{\mathbf{u}}_{2}^{\prime} \overline{\mathbf{u}}_{2}\right] \\
& \gamma_{1,3}=-2 n^{-1} E\left[\overline{\overline{\mathbf{u}}}_{12}^{\prime} \overline{\mathbf{u}}_{1}-\operatorname{Tr}\left\{\mathbf{W}_{1} \operatorname{diag}_{i=1}^{N}\left[\left(E \bar{u}_{2 i} \bar{u}_{1 i}\right)\right] \mathbf{W}_{1}^{\prime}\right\}\right] \\
& \gamma_{2,3}=-n^{-1} E\left[\overline{\overline{\mathbf{u}}}_{12}^{\prime} \overline{\mathbf{u}}_{1}+\overline{\overline{\mathbf{u}}}_{1}^{\prime} \overline{\mathbf{u}}_{2}\right]
\end{aligned}
$$




$$
\begin{aligned}
& \gamma_{3,3}=-2 n^{-1} E\left[\overline{\mathbf{u}}_{2}^{\prime} \overline{\overline{\mathbf{u}}}_{21}-\operatorname{Tr}\left\{\mathbf{W}_{2} \operatorname{diag}_{i=1}^{N}\left[\left(E \bar{u}_{2 i} \bar{u}_{1 i}\right)\right] \mathbf{W}_{2}^{\prime}\right\}\right] \\
& \gamma_{4,3}=-n^{-1} E\left[\overline{\overline{\mathbf{u}}}_{2}^{\prime} \overline{\mathbf{u}}_{1}+\overline{\overline{\mathbf{u}}}_{21}^{\prime} \overline{\mathbf{u}}_{2}\right] \\
& \gamma_{1,4}=-n^{-1} E\left[\overline{\overline{\mathbf{u}}}_{1}^{\prime} \overline{\mathbf{u}}_{1}-\operatorname{Tr}\left\{\mathbf{W}_{1} \operatorname{diag}_{i=1}^{N}\left[\left(E \bar{u}_{1 i} \bar{u}_{1 i}\right)\right] \mathbf{W}_{1}^{\prime}\right\}\right] \\
& \gamma_{2,4}=-n^{-1} E\left[\overline{\overline{\mathbf{u}}}_{1}^{\prime} \overline{\mathbf{u}}_{1}\right] \\
& \gamma_{3,4}=-n^{-1} E\left[\overline{\overline{\mathbf{u}}}_{21}^{\prime} \overline{\overline{\mathbf{u}}}_{21}-\operatorname{Tr}\left\{\mathbf{W}_{2} \operatorname{diag}_{i=1}^{N}\left[\left(E \bar{u}_{1 i} \bar{u}_{1 i}\right)\right] \mathbf{W}_{2}^{\prime}\right\}\right] \\
& \gamma_{4,4}=-n^{-1} E\left[\overline{\overline{\mathbf{u}}}_{21}^{\prime} \overline{\mathbf{u}}_{1}\right] \\
& \gamma_{1,5}=-n^{-1} E\left[\overline{\overline{\mathbf{u}}}_{12}^{\prime} \overline{\overline{\mathbf{u}}}_{12}-\operatorname{Tr}\left\{\mathbf{W}_{1} \operatorname{diag}_{i=1}^{N}\left[\left(E \bar{u}_{2 i} \bar{u}_{2 i}\right)\right] \mathbf{W}_{1}^{\prime}\right\}\right] \\
& \gamma_{2,5}=-n^{-1} E\left[\overline{\overline{\mathbf{u}}}_{12}^{\prime} \overline{\mathbf{u}}_{2}\right] \\
& \gamma_{3,5}=-n^{-1} E\left[\overline{\overline{\mathbf{u}}}_{2}^{\prime} \overline{\mathbf{u}}_{2}-\operatorname{Tr}\left\{\mathbf{W}_{2} \operatorname{diag}_{i=1}^{N}\left[\left(E \bar{u}_{2 i} \bar{u}_{2 i}\right)\right] \mathbf{W}_{2}^{\prime}\right\}\right] \\
& \gamma_{4,5}=-n^{-1} E\left[\overline{\overline{\mathbf{u}}}_{2}^{\prime} \overline{\mathbf{u}}_{2}\right]
\end{aligned}
$$

Under homoskedasticity, the moment conditions are derived the same way and simplify to (A.12), where each expression involving the trace operator is replaced by its counterpart under homoskedasticity, e.g. the element $\gamma_{1,1}=2 n^{-1} E\left[\overline{\overline{\mathbf{u}}}_{1}^{\prime} \overline{\mathbf{u}}_{1}-\operatorname{Tr}\left(\mathbf{W}_{1} \operatorname{diag}\left(\bar{u}_{1 i} u_{i}\right) \mathbf{W}_{1}^{\prime}\right)\right]$ becomes $2 n^{-1} E\left[\overline{\overline{\mathbf{u}}}_{1}^{\prime} \overline{\mathbf{u}}_{1}-\overline{\mathbf{u}}_{1}^{\prime} \mathbf{u} n^{-1} \operatorname{Tr}\left(\mathbf{W}_{1} \mathbf{W}_{1}^{\prime}\right)\right]$; analogously for all other expressions where the trace operator appears; the other elements are not affected.

The GM estimates of $\rho_{1}$ and $\rho_{2}$ are obtained by solving the nonlinear optimization problem

$$
\left[\tilde{\rho}_{1} \tilde{\rho}_{2}\right]=\underset{\rho_{1}, \rho_{2}}{\operatorname{argmin}}\left[(\tilde{\boldsymbol{\gamma}}-\tilde{\boldsymbol{\Gamma}} \boldsymbol{\alpha})^{\prime} \mathbf{\Omega}(\tilde{\boldsymbol{\gamma}}-\tilde{\boldsymbol{\Gamma}} \boldsymbol{\alpha})\right],
$$

where $\tilde{\gamma}$ and $\tilde{\boldsymbol{\Gamma}}$ are the estimates of $\gamma$ and $\Gamma$, whose elements are obtained from (A.12) by suppressing the expectations operator and replacing the disturbances $\mathbf{u}$ by their estimates. The identity matrix can be used as weights matrix $\Omega$ to obtain consistent estimates of $\rho_{1}$ and $\rho_{2}$.

\section{A2.2.2 Some Monte Carlo Evidence}

In this section we assess the small sample performance of the GM estimator (A.13) for $\rho_{1}$ and $\rho_{2}$, considering the spatial regressive error process (A.8). We use three sample sizes: $N=100$, $\mathrm{N}=250$, and $\mathrm{N}=500$ observations.

For our basic setup of the weights matrix we follow Kelejian and Prucha (1999) and use a binary " 5 ahead and 5 behind specification". This means that the elements of the raw weights matrix $\mathbf{W}^{\mathbf{0}}$ are defined such that the $i$-th element of $\mathbf{u}$ is related to the five elements after it and the five elements before it. In line with Kelejian and Prucha (2007) we modify the inner third of $\mathbf{W}^{\mathbf{0}}$ such that each element has only two neighbours, one before and one behind. This introduces some variation in the row sums.

The novel feature of this Monte Carlos study is that the matrix $\mathbf{W}^{\mathbf{0}}$ is then split up into two matrices $\mathbf{W}_{1}^{0}$ and $\mathbf{W}_{2}^{0}$, where $\mathbf{W}_{1}^{0}+\mathbf{W}_{2}^{0}=\mathbf{W}^{0}$. The elements of $\mathbf{W}_{1}^{0}$ are chosen such that its columns $\mathbf{w}_{1, j}^{0}$ are equal to that of $\mathbf{W}$ for $j=1, \ldots, 5 ; 11, \ldots, 15 ; 21, \ldots, 25$, etc., i.e., $\mathbf{w}_{1, j}^{0}=\mathbf{w}_{. j}^{0}$, for $j=1+10 s, 2+10 s, 3+10 s, 4+10 s, 5+10 s ; s=0,1,2, \ldots . S$ (where $\mathrm{S}$ depends on the sample size) and $\mathbf{w}_{1, j}^{0}=0$ otherwise. Accordingly, $\mathbf{w}_{2, . j}^{0}=\mathbf{w}_{. j}^{0}$, for $j=6+10 s, 7+10 s$, $8+10 s, 9+10 s, 10+10 s ; s=0,1,2, \ldots . S$ and $\mathbf{w}_{2, j}^{0}=0$ otherwise. The final weights matrices 
$\mathbf{W}_{1}$ and $\mathbf{W}_{2}$ are obtained by separately row-normalizing $\mathbf{W}_{1}^{0}$ and $\mathbf{W}_{2}^{0}$, that is by dividing their elements $w_{1, i j}^{0}$ and $w_{2, i j}^{0}$ through the row sums $d_{1, i}$ and $d_{2, i}$ respectively.

For two row-normalized matrices $\mathbf{W}_{1}$ and $\mathbf{W}_{2}$ the parameter space for $\rho_{1}$ and $\rho_{2}$ must satisfy $0 \leq\left|\rho_{1}\right|+\left|\rho_{2}\right|<1$ for (I $\left.-\rho_{1} \mathbf{W}_{1}-\rho_{2} \mathbf{W}_{2}\right)$ to be invertible (Lee and Xiaodong, 2006). The values of the true parameters $\rho_{1}$ and $\rho_{2}$ are chosen to range from -0.4 to +0.4 , with increments of 0.2 . Hence, we have 25 possible parameter combinations $\left\{\left(\rho_{1}, \rho_{2}\right) \mid \rho_{1}, \rho_{2} \in(-\right.$ $0.4,-0.2,0,0.2,0.4)\}$.

Regarding the properties of the error term $\varepsilon$ we consider both homo- and heteroskedasticity. Let $\xi_{i}$ denote a draw from a standard normal distribution. In line with Kelejian and Prucha (2007) the innovations were generated as $\varepsilon_{i}=\sigma \xi_{i}$ with $\sigma^{2}=2$ under homoskedasticity and $\varepsilon_{i}=$ as $\sigma_{i} \xi_{i}$ with $\sigma_{i}^{2}=d_{i} / 4$ under heteroskedasticity, where $d_{i}$ denotes the $i$-th row sum of the unnormalized matrix. For each Monte Carlo experiment we considered 2000 draws. To improve comparability, the same draw of $\xi$ was used for both homo- and heteroskedasticity and for each of the 25 possible combinations of $\rho_{1}$ and $\rho_{2}$.

Tables A2.1 to A2.3 report the results for the three different sample sizes both under homo- and heteroskedasticity. The results suggest that the estimator performs reasonably well, even in small samples. As can be seen from Table A2.1, which is based on a sample size of 100 observations, the bias over all parameter constellations is fairly small, with an average absolute bias of 0.023 under homoskedasticity and one of 0.036 under heteroskedasticity. This is less than 10 and 15 percent, respectively, in relative terms. Moreover, the results suggest that the parameter estimates tend to be downward biased, in particular for true values around zero, where the estimates are slightly negative. Increasing the sample size to 250 (500) observations the average bias is reduced to 0.010 (0.004) under homoscedasticity and 0.013 (0.008) under heteroscedasticity, corresponding to 4.167 (1.750) and 5.417 (3.333) percent, respectively, in relative terms. 
Table A2.1 Monte Carlo Results, $\mathrm{N}=100,2000$ draws

\begin{tabular}{|c|c|c|c|c|c|c|c|c|c|}
\hline & & \multicolumn{4}{|c|}{ Homoskedasticity } & \multicolumn{4}{|c|}{ Heteroskedasticity } \\
\hline \multicolumn{2}{|c|}{ True Parameters } & \multicolumn{2}{|c|}{ Bias } & \multicolumn{2}{|c|}{ RMSE } & \multicolumn{2}{|c|}{ Bias } & \multicolumn{2}{|c|}{ RMSE } \\
\hline$\rho_{1}$ & $\rho_{2}$ & $\hat{\rho}_{1}$ & $\hat{\rho}_{2}$ & $\hat{\rho}_{1}$ & $\hat{\rho}_{2}$ & $\hat{\rho}_{1}$ & $\hat{\rho}_{2}$ & $\hat{\rho}_{1}$ & $\hat{\rho}_{2}$ \\
\hline-0.4 & -0.4 & 0.004 & -0.002 & 0.107 & 0.108 & 0.010 & 0.011 & 0.132 & 0.135 \\
\hline-0.4 & -0.2 & 0.015 & -0.038 & 0.116 & 0.158 & 0.017 & -0.042 & 0.138 & 0.194 \\
\hline-0.4 & 0 & 0.019 & -0.045 & 0.121 & 0.172 & 0.019 & -0.059 & 0.141 & 0.217 \\
\hline-0.4 & 0.2 & 0.022 & -0.044 & 0.123 & 0.166 & 0.020 & -0.058 & 0.143 & 0.208 \\
\hline-0.4 & 0.4 & 0.025 & -0.042 & 0.126 & 0.147 & 0.023 & -0.055 & 0.145 & 0.181 \\
\hline-0.2 & -0.4 & -0.029 & 0.010 & 0.153 & 0.117 & -0.039 & 0.018 & 0.187 & 0.142 \\
\hline-0.2 & -0.2 & -0.018 & -0.027 & 0.157 & 0.162 & -0.033 & -0.036 & 0.190 & 0.197 \\
\hline-0.2 & 0 & -0.015 & -0.034 & 0.158 & 0.174 & -0.031 & -0.051 & 0.192 & 0.218 \\
\hline-0.2 & 0.2 & -0.012 & -0.033 & 0.159 & 0.166 & -0.031 & -0.048 & 0.193 & 0.208 \\
\hline-0.2 & 0.4 & -0.007 & -0.029 & 0.158 & 0.144 & -0.028 & -0.042 & 0.192 & 0.178 \\
\hline 0 & -0.4 & -0.037 & 0.015 & 0.167 & 0.123 & -0.052 & 0.020 & 0.205 & 0.145 \\
\hline 0 & -0.2 & -0.027 & -0.022 & 0.168 & 0.164 & -0.044 & -0.035 & 0.205 & 0.199 \\
\hline 0 & 0 & -0.023 & -0.030 & 0.168 & 0.174 & -0.041 & -0.049 & 0.207 & 0.219 \\
\hline 0 & 0.2 & -0.020 & -0.028 & 0.167 & 0.164 & -0.042 & -0.045 & 0.208 & 0.207 \\
\hline 0 & 0.4 & -0.014 & -0.024 & 0.162 & 0.140 & -0.037 & -0.037 & 0.201 & 0.175 \\
\hline 0.2 & -0.4 & -0.038 & 0.018 & 0.161 & 0.126 & -0.052 & 0.021 & 0.196 & 0.147 \\
\hline 0.2 & -0.2 & -0.027 & -0.018 & 0.161 & 0.165 & -0.040 & -0.035 & 0.195 & 0.199 \\
\hline 0.2 & 0 & -0.023 & -0.026 & 0.159 & 0.174 & -0.036 & -0.049 & 0.195 & 0.219 \\
\hline 0.2 & 0.2 & -0.020 & -0.025 & 0.156 & 0.163 & -0.035 & -0.044 & 0.194 & 0.205 \\
\hline 0.2 & 0.4 & -0.014 & -0.021 & 0.147 & 0.136 & -0.029 & -0.034 & 0.180 & 0.170 \\
\hline 0.4 & -0.4 & -0.037 & 0.024 & 0.146 & 0.130 & -0.051 & 0.024 & 0.175 & 0.149 \\
\hline 0.4 & -0.2 & -0.025 & -0.011 & 0.143 & 0.165 & -0.036 & -0.030 & 0.170 & 0.197 \\
\hline 0.4 & 0 & -0.020 & -0.019 & 0.139 & 0.170 & -0.030 & -0.041 & 0.167 & 0.208 \\
\hline 0.4 & 0.2 & -0.018 & -0.017 & 0.133 & 0.155 & -0.027 & -0.034 & 0.162 & 0.188 \\
\hline 0.4 & 0.4 & -0.010 & -0.013 & 0.120 & 0.126 & -0.019 & -0.024 & 0.142 & 0.150 \\
\hline 0.24 & 0.24 & 0.021 & 0.025 & 0.147 & 0.152 & 0.033 & 0.038 & 0.178 & 0.186 \\
\hline
\end{tabular}

Note: Last row shows average value of absolute values in the respective column. RMSE denotes root mean squared error. 
Table A2.2 Monte Carlo Results, N = 250, 2000 draws

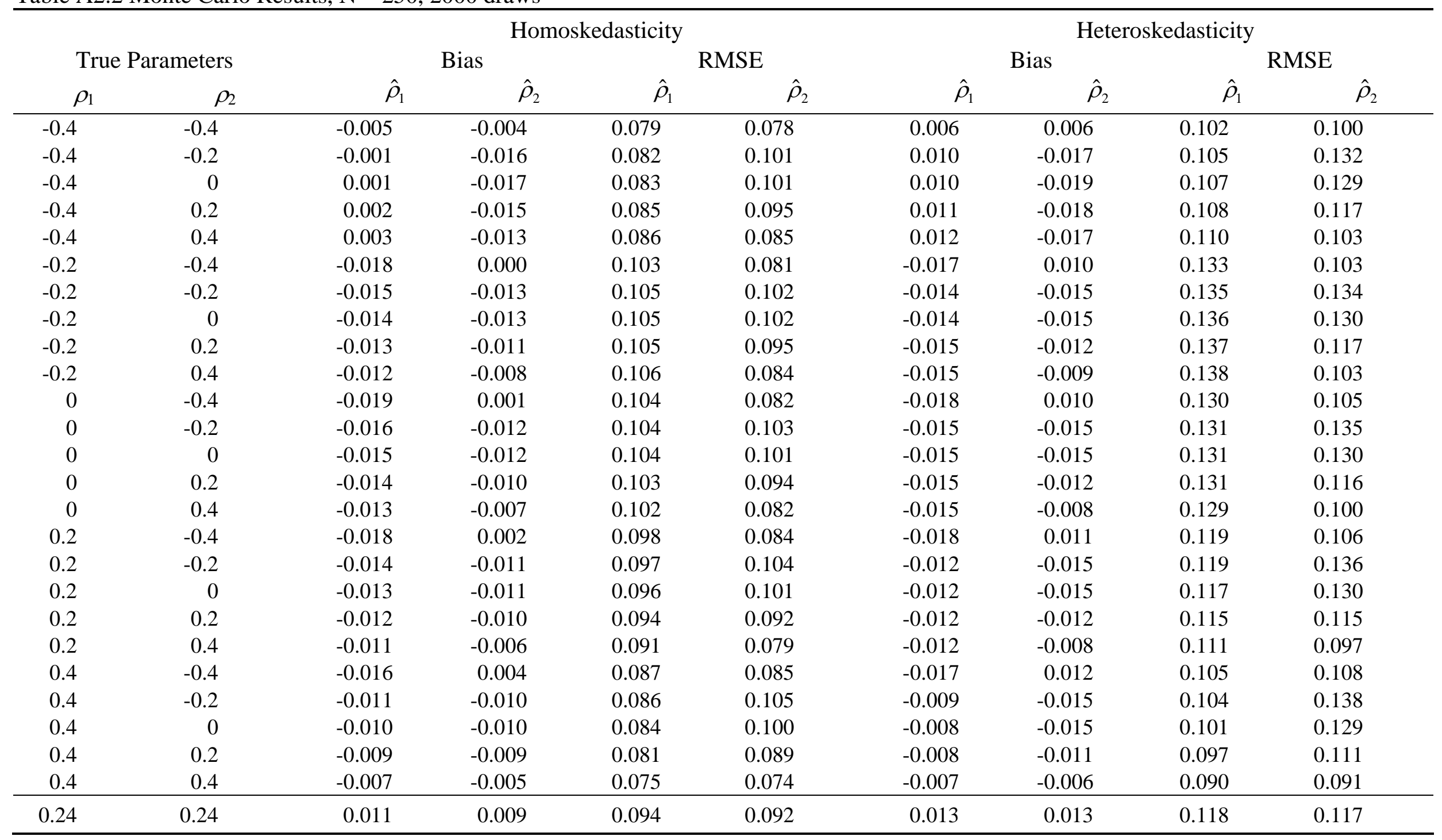

Note: See Table A2.1. 
Table A2.3 Monte Carlo Results, $\mathrm{N}=$ 500, 2000 draws

\begin{tabular}{|c|c|c|c|c|c|c|c|c|c|}
\hline & & \multicolumn{4}{|c|}{ Homoskedasticity } & \multicolumn{4}{|c|}{ Heteroskedasticity } \\
\hline \multicolumn{2}{|c|}{ True Parameters } & \multicolumn{2}{|c|}{ Bias } & \multicolumn{2}{|c|}{ RMSE } & \multicolumn{2}{|c|}{ Bias } & \multicolumn{2}{|c|}{ RMSE } \\
\hline$\rho_{1}$ & $\rho_{2}$ & $\hat{\rho}_{1}$ & $\hat{\rho}_{2}$ & $\hat{\rho}_{1}$ & $\hat{\rho}_{2}$ & $\hat{\rho}_{1}$ & $\hat{\rho}_{2}$ & $\hat{\rho}_{1}$ & $\hat{\rho}_{2}$ \\
\hline-0.4 & -0.4 & -0.003 & -0.003 & 0.062 & 0.062 & -0.002 & -0.002 & 0.080 & 0.080 \\
\hline-0.4 & -0.2 & -0.002 & -0.002 & 0.064 & 0.064 & 0.000 & 0.000 & 0.082 & 0.082 \\
\hline-0.4 & 0 & -0.001 & -0.001 & 0.065 & 0.065 & 0.000 & 0.000 & 0.083 & 0.083 \\
\hline-0.4 & 0.2 & 0.000 & 0.000 & 0.066 & 0.066 & 0.000 & 0.000 & 0.084 & 0.084 \\
\hline-0.4 & 0.4 & 0.000 & 0.000 & 0.067 & 0.067 & 0.001 & 0.001 & 0.085 & 0.085 \\
\hline-0.2 & 0 & -0.006 & -0.006 & 0.074 & 0.074 & -0.012 & -0.012 & 0.097 & 0.097 \\
\hline-0.2 & 0.2 & -0.005 & -0.005 & 0.075 & 0.075 & -0.012 & -0.012 & 0.099 & 0.099 \\
\hline-0.2 & 0.4 & -0.005 & -0.005 & 0.075 & 0.075 & -0.013 & -0.013 & 0.100 & 0.100 \\
\hline 0 & -0.4 & -0.008 & -0.008 & 0.072 & 0.072 & -0.012 & -0.012 & 0.090 & 0.090 \\
\hline 0 & -0.2 & -0.006 & -0.006 & 0.072 & 0.072 & -0.010 & -0.010 & 0.090 & 0.090 \\
\hline 0 & 0 & -0.006 & -0.006 & 0.072 & 0.072 & -0.010 & -0.010 & 0.090 & 0.090 \\
\hline 0.2 & 0 & -0.005 & -0.005 & 0.066 & 0.066 & -0.009 & -0.009 & 0.080 & 0.080 \\
\hline 0.2 & 0.2 & -0.005 & -0.005 & 0.065 & 0.065 & -0.009 & -0.009 & 0.079 & 0.079 \\
\hline 0.2 & 0.4 & -0.004 & -0.004 & 0.063 & 0.063 & -0.009 & -0.009 & 0.077 & 0.077 \\
\hline 0.4 & -0.4 & -0.006 & -0.006 & 0.060 & 0.060 & -0.010 & -0.010 & 0.072 & 0.072 \\
\hline 0.4 & -0.2 & -0.004 & -0.004 & 0.060 & 0.060 & -0.007 & -0.007 & 0.072 & 0.072 \\
\hline 0.4 & 0 & -0.003 & -0.003 & 0.058 & 0.058 & -0.006 & -0.006 & 0.070 & 0.070 \\
\hline 0.4 & 0.2 & -0.003 & -0.003 & 0.056 & 0.056 & -0.006 & -0.006 & 0.067 & 0.067 \\
\hline 0.4 & 0.4 & -0.002 & -0.002 & 0.052 & 0.052 & -0.006 & -0.006 & 0.062 & 0.062 \\
\hline 0.24 & 0.24 & 0.004 & 0.004 & 0.067 & 0.067 & 0.008 & 0.008 & 0.084 & 0.084 \\
\hline
\end{tabular}

Note: See Table A2.1. 


\section{Appendix A3. Construction of Predicted Weights Matrices}

The construction of the predicted weights matrix $\hat{\mathbf{W}}^{\text {UD,in }}$ proceeds as flows. In a first step, the following gravity type model is estimated:

$$
\ln w_{i k, j l}^{0}=\kappa_{i, k}+\eta_{j, l}+\gamma_{j, l} \ln D I S T_{i, k}+\omega_{i k, j l},
$$

where $w_{i k, j l}^{0}$ is the use-plus-delivery intensity as defined in equation (5), $\kappa_{i, k}$ is a set of country-pair dummies $(i, k=1, \ldots, 13)$ and $\eta_{j, l}$ is a set of industry-pair dummies $(j, l=1, \ldots$, 15). $D I S T_{i, k}$ denotes average distance between countries $i$ and $k$ (or, for $i=k$, internal distance defined as $D I S T_{i, i}=0.67 \sqrt{A R E A_{i} / \pi}$ ); its parameter is allowed to vary across industry-pairs. The data source for distance $D I S T_{i, k}$ is the CEPII database (see Mayer and Zignago, 2006).

The model in (A.14) has potentially 619 parameters. For use-plus-delivery intensities, there are 37094 non-zero observations (of potentially $195 \times 195=38025$ ). One could avoid losing observations by employing a Poisson quasi-maximum likelihood model as suggested by Santos Silva and Tenreyro (2006). However, the latter obtains very similar effects in our case. Results indicate that the model performs reasonably well in predicting input-output flows. With an $R^{2}$ of 0.809 the model explains a substantial part of the variation in use-plusdelivery intensity across countries and industries. Hence, model (A.14) serves our purpose well, given our goal to generate exogenous weights from predicted values.

The parameter estimates of model (A.14) are then used to generate the predicted weights matrix as follows:

$$
\hat{w}_{i k, j l}^{0}=\exp \left(\hat{\kappa}_{i, k}+\hat{\eta}_{j, l}+\hat{\gamma}_{j, l} \ln D I S T_{i, k}\right) .^{24}
$$

For observations with a zero entry, the predictions are set to zero as well. The predicted values $\hat{w}_{i k, j l}^{0}$ are used to set up the unnormalized predicted weights matrix $\hat{\mathbf{W}}^{\mathbf{U D}, 0}=\left[\hat{w}_{i j, k l}^{0}\right]$, which is row-normalized to obtain the final predicted weights matrix $\hat{\mathbf{W}}^{\mathbf{U D} \text {,in }}$.

The construction of the predicted weights matrices reflecting intra- and inter-industry use-plus-delivery intensities $\hat{\mathbf{W}}_{\text {intra }}^{\text {UD,in }}$ and $\hat{\mathbf{W}}_{\text {inter }}^{\text {UD,in }}$ proceeds the same way as for the original weights matrix (see subsection 2 in section III). Finally, if $w_{i k, j l}^{0}$ in (A.14) is defined as use or delivery intensity (rather than use-plus-delivery intensity), the same procedure can be applied to obtain the predicted weights matrices based on use $\left(\hat{\mathbf{W}}^{\mathbf{U} \text {,in }}\right)$ or delivery intensity ( $\left.\hat{\mathbf{W}}^{\mathbf{D} \text {,in }}\right)$.

${ }^{24}$ The conditional expectation of $w$ is equal to $\exp \left(\hat{\kappa}_{i, k}+\hat{\eta}_{j, l}+\hat{\gamma}_{j, l} \ln D I S T_{i, k}\right)$ times $E\left[\exp \left(\omega_{i k, j l}\right)\right]$ (see Frankel and Romer, 1999, p. 384). Under normality $E\left[\exp \left(\omega_{i k, j l}\right)\right]=\exp \left[\left(\sigma_{i k, j l}^{2} / 2\right)\right]$, where $\sigma_{i k, j l}^{2}$ is the variance of $\omega_{i k, j l}$. Since $\omega$ is modelled as homoskedastic, this correction factor is the same for all observations and can be dropped without consequences for the results regarding the final row-standardized weights matrix. 


\section{CESifo Working Paper Series}

for full list see www.cesifo-group.org/wp

(address: Poschingerstr. 5, 81679 Munich, Germany, office@cesifo.de)

2116 Katrin Assenmacher-Wesche and M. Hashem Pesaran, Assessing Forecast Uncertainties in a VECX Model for Switzerland: An Exercise in Forecast Combination across Models and Observation Windows, October 2007

2117 Ben Lockwood, Voting, Lobbying, and the Decentralization Theorem, October 2007

2118 Andrea Ichino, Guido Schwerdt, Rudolf Winter-Ebmer and Josef Zweimüller, Too Old to Work, too Young to Retire?, October 2007

2119 Wolfgang Eggert, Tim Krieger and Volker Meier, Education, Unemployment and Migration, October 2007

2120 Stefan Napel and Mika Widgrén, The European Commission - Appointment, Preferences, and Institutional Relations, October 2007

2121 Bertil Holmlund and Martin Söderström, Estimating Income Responses to Tax Changes: A Dynamic Panel Data Approach, October 2007

2122 Doina Maria Radulescu, From Separate Accounting to Formula Apportionment: Analysis in a Dynamic Framework, October 2007

2123 Jelle Brouwer, Richard Paap and Jean-Marie Viaene, The Trade and FDI Effects of EMU Enlargement, October 2007

2124 Kurt R. Brekke, Luigi Siciliani and Odd Rune Straume, Competition and Waiting Times in Hospital Markets, October 2007

2125 Alexis Direr, Flexible Life Annuities, October 2007

2126 Johannes Becker and Clemens Fuest, Quality versus Quantity - The Composition Effect of Corporate Taxation on Foreign Direct Investment, October 2007

2127 Balázs Égert, Real Convergence, Price Level Convergence and Inflation Differentials in Europe, October 2007

2128 Marko Koethenbuerger, Revisiting the "Decentralization Theorem" - On the Role of Externalities, October 2007

2129 Axel Dreher, Silvia Marchesi and James Raymond Vreeland, The Politics of IMF Forecasts, October 2007

2130 Andreas Knabe and Ronnie Schöb, Subsidizing Extra Jobs: Promoting Employment by Taming the Unions, October 2007 
2131 Michel Beine and Bertrand Candelon, Liberalization and Stock Market Co-Movement between Emerging Economies, October 2007

2132 Dieter M. Urban, FDI Technology Spillovers and Wages, October 2007

2133 Valentina Bosetti, Carlo Carraro, Emanuele Massetti and Massimo Tavoni, Optimal Energy Investment and R\&D Strategies to Stabilise Greenhouse Gas Atmospheric Concentrations, October 2007

2134 David-Jan Jansen and Jakob de Haan, The Importance of Being Vigilant: Has ECB Communication Influenced Euro Area Inflation Expectations?, October 2007

2135 Oliver Falck, Heavyweights - The Impact of Large Businesses on Productivity Growth, October 2007

2136 Xavier Freixas and Bruno M. Parigi, Banking Regulation and Prompt Corrective Action, November 2007

2137 Jan K. Brueckner, Partial Fiscal Decentralization, November 2007

2138 Silvia Console Battilana, Uncovered Power: External Agenda Setting, Sophisticated Voting, and Transnational Lobbying, November 2007

2139 Alan J. Auerbach, Michael P. Devereux and Helen Simpson, Taxing Corporate Income, November 2007

2140 Lorenzo Cappellari, Paolo Ghinetti and Gilberto Turati, On Time and Money Donations, November 2007

2141 Roel Beetsma and Heikki Oksanen, Pension Systems, Ageing and the Stability and Growth Pact, November 2007

2142 Hikaru Ogawa and David E. Wildasin, Think Locally, Act Locally: Spillovers, Spillbacks, and Efficient Decentralized Policymaking, November 2007

2143 Alessandro Cigno, A Theoretical Analysis of the Effects of Legislation on Marriage, Fertility, Domestic Division of Labour, and the Education of Children, November 2007

2144 Kai A. Konrad, Mobile Tax Base as a Global Common, November 2007

2145 Ola Kvaløy and Trond E. Olsen, The Rise of Individual Performance Pay, November 2007

2146 Guglielmo Maria Caporale, Yannis Georgellis, Nicholas Tsitsianis and Ya Ping Yin, Income and Happiness across Europe: Do Reference Values Matter?, November 2007

2147 Dan Anderberg, Tax Credits, Income Support and Partnership Decisions, November 2007 
2148 Andreas Irmen and Rainer Klump, Factor Substitution, Income Distribution, and Growth in a Generalized Neoclassical Model, November 2007

2149 Lorenz Blume, Jens Müller and Stefan Voigt, The Economic Effects of Direct Democracy - A First Global Assessment, November 2007

2150 Axel Dreher, Pierre-Guillaume Méon and Friedrich Schneider, The Devil is in the Shadow - Do Institutions Affect Income and Productivity or only Official Income and Official Productivity?, November 2007

2151 Valentina Bosetti, Carlo Carraro, Emanuele Massetti and Massimo Tavoni, International Energy R\&D Spillovers and the Economics of Greenhouse Gas Atmospheric Stabilization, November 2007

2152 Balázs Égert and Dubravko Mihaljek, Determinants of House Prices in Central and Eastern Europe, November 2007

2153 Christa Hainz and Hendrik Hakenes, The Politician and his Banker, November 2007

2154 Josef Falkinger, Distribution and Use of Knowledge under the "Laws of the Web", December 2007

2155 Thorvaldur Gylfason and Eduard Hochreiter, Growing Apart? A Tale of Two Republics: Estonia and Georgia, December 2007

2156 Morris A. Davis and François Ortalo-Magné, Household Expenditures, Wages, Rents, December 2007

2157 Andreas Haufler and Christian Schulte, Merger Policy and Tax Competition, December 2007

2158 Marko Köthenbürger and Panu Poutvaara, Rent Taxation and its Intertemporal Welfare Effects in a Small Open Economy, December 2007

2159 Betsey Stevenson, Title IX and the Evolution of High School Sports, December 2007

2160 Stergios Skaperdas and Samarth Vaidya, Persuasion as a Contest, December 2007

2161 Morten Bennedsen and Christian Schultz, Arm’s Length Provision of Public Services, December 2007

2162 Bas Jacobs, Optimal Redistributive Tax and Education Policies in General Equilibrium, December 2007

2163 Christian Jaag, Christian Keuschnigg and Mirela Keuschnigg, Pension Reform, Retirement and Life-Cycle Unemployment, December 2007

2164 Dieter M. Urban, Terms of Trade, Catch-up, and Home Market Effect: The Example of Japan, December 2007 
2165 Marcelo Resende and Rodrigo M. Zeidan, Lionel Robbins: A Methodological Reappraisal, December 2007

2166 Samuel Bentolila, Juan J. Dolado and Juan F. Jimeno, Does Immigration Affect the Phillips Curve? Some Evidence for Spain, December 2007

2167 Rainald Borck, Federalism, Fertility and Growth, December 2007

2168 Erkki Koskela and Jan König, Strategic Outsourcing, Profit Sharing and Equilibrium Unemployment, December 2007

2169 Egil Matsen and Øystein Thøgersen, Habit Formation, Strategic Extremism and Debt Policy, December 2007

2170 Torben M. Andersen and Allan Sørensen, Product Market Integration and Income Taxation: Distortions and Gains from Trade, December 2007

2171 J. Atsu Amegashie, American Idol: Should it be a Singing Contest or a Popularity Contest?, December 2007

2172 Patricia Apps and Ray Rees, Household Models: An Historical Perspective, December 2007

2173 Ben Greiner, Axel Ockenfels and Peter Werner, The Dynamic Interplay of Inequality and Trust - An Experimental Study, December 2007

2174 Michael Melvin and Magali Valero, The Dark Side of International Cross-Listing: Effects on Rival Firms at Home, December 2007

2175 Gebhard Flaig and Horst Rottmann, Labour Market Institutions and the Employment Intensity of Output Growth. An International Comparison, December 2007

2176 Alexander Chudik and M. Hashem Pesaran, Infinite Dimensional VARs and Factor Models, December 2007

2177 Christoph Moser and Axel Dreher, Do Markets Care about Central Bank Governor Changes? Evidence from Emerging Markets, December 2007

2178 Alessandra Sgobbi and Carlo Carraro, A Stochastic Multiple Players Multi-Issues Bargaining Model for the Piave River Basin, December 2007

2179 Christa Hainz, Creditor Passivity: The Effects of Bank Competition and Institutions on the Strategic Use of Bankruptcy Filings, December 2007

2180 Emilia Del Bono, Andrea Weber and Rudolf Winter-Ebmer, Clash of Career and Family: Fertility Decisions after Job Displacement, January 2008

2181 Harald Badinger and Peter Egger, Intra- and Inter-Industry Productivity Spillovers in OECD Manufacturing: A Spatial Econometric Perspective, January 2008 